\title{
Optimal Emission Prices Over the Business Cycles
}

\author{
Jussi Lintunen ${ }^{1,2}$ (D) Lauri Vilmi ${ }^{3}$
}

Accepted: 27 June 2021 / Published online: 2 August 2021

(C) The Author(s) 2021

\begin{abstract}
We prove that under the most typical circumstances optimal emission prices are procyclical, i.e., prices should be lower during recessions. The procyclicality is more likely when emissions propagate very slowly into environmental damage. A prime example of such process is $\mathrm{CO}_{2}$ emissions. We show that carbon prices should be closely linked to the fluctuations of the marginal utility of consumption, which implies relatively modest magnitude of carbon price fluctuations. Our findings imply that climate policies should focus on setting the carbon price to the optimal growth path level and give carbon price fluctuations only a secondary role. Opposite to the carbon price, the cyclicality of optimal emissions depends on the production technology in the energy sector, and may become countercyclical in future if the technology mix becomes less fossil dependent.
\end{abstract}

Keywords Pigouvian emission price $\cdot$ Social cost of carbon $\cdot$ Cyclical properties $\cdot$ DSGE . Emission tax $\cdot$ Cap and trade

JEL Classification E32 $\cdot$ Q54 · Q58

\section{Introduction}

The EU emission trading system (EU ETS) witnessed a dramatic allowance price drop from $25 € / \mathrm{t}_{\mathrm{CO}_{2}}$ to $5 € / \mathrm{t}_{\mathrm{CO}_{2}}$ during a five year period 2008-2013. The price decline occurred simultaneously with an economic downturn and the low price persisted until early 2018. As a result of economic recovery and policy changes the price has steadily increased during 2018 and later in 2020-2021. It has been unclear whether such large scale price fluctuations exist in the first best climate policy. The question of business cycle fluctuations of emission prices is clearly connected to a general discussion on optimal adjustment of

Jussi Lintunen

Jussi.lintunen@luke.fi; Jussi.lintunen@etla.fi

Lauri Vilmi

Lauri.vilmi@bof.fi

1 Natural Resources Institute Finland (Luke), Latokartanonkaari 7, 00790 Helsinki, Finland

2 ETLA Economic Research, Arkadiankatu 23B, 00100 Helsinki, Finland

3 Bank of Finland, Helsinki, Finland 
environmental policy, when economic activity varies (e.g. van den Bijgaart and Smulders 2018).

Given the Pigouvian principles (Pigou 1932), the carbon price should equal the marginal damage of the carbon externality, ${ }^{1}$ which is called the social cost of carbon (SCC). ${ }^{2}$ We examine how the SCC and the resulting emissions vary over the business cycles. Previous studies (Heutel 2012; Angelopoulos et al. 2013; Annicchiarico and Di Dio 2015; Grodecka and Kuralbayeva 2015) have suggested that carbon price fluctuations should be procyclical, but the underlying mechanism has not been studied thoroughly. We show that the procyclicality follows from the procyclical consumption fluctuations that drive the SCC fluctuations. This implies relatively modest carbon price fluctuations. As a result, the SCC seems to have a relatively weak effect on the fluctuation of emissions, which are mostly dictated by the technology in polluting sector. To fix ideas, we call the polluting sector as energy sector, which is the main source of anthropogenic $\mathrm{CO}_{2}$ emissions (e.g. Climate Watch 2020).

We build an environment-economy dynamic stochastic general equilibrium (DSGE) model of real business cycles (RBC). Our modeling provides four important deviations from previous carbon tax business cycle studies (Heutel 2012; Angelopoulos et al. 2013; Annicchiarico and Di Dio 2015; Grodecka and Kuralbayeva 2015). ${ }^{3}$ First, we apply a detailed climate model with separate atmospheric carbon stocks and global temperature (e.g. Nordhaus 2014), which provides up-to-date description of the climate science (IPCC 2013). Second, our analytical results are based on a lag-structure approach depicting a general emission-environment dynamical system (cf. Gerlagh and Liski 2018b) that allows for extending the analysis beyond the atmospheric carbon externality. Third, we follow the approach by Golosov et al. (2014) and directly connect the emissions to the polluting input use. Thus, we do not rely on the production level driven emissions nor an explicit abatement variable. Instead, our technology description focuses on substitution of capital intensive green energy technologies for fossil fuels, i.e., the technology portfolio is summarized by the elasticity of substitution between energy sector capital and polluting input. With such an approach, we can examine the role of production technology of the energy sector in determining the dynamic properties of the SCC and carbon emissions. Fourth, we derive an analytical formulation for the general Pigouvian emission price and decompose its fluctuations around a growth path. Several formulas have been presented for the SCC but these have focused only on the level of the SCC (Golosov et al. 2014; Gerlagh and Liski 2018b; van den Bijgaart et al. 2016; van den Bremer and van der Ploeg 2019). To study the cyclical properties of the SCC, we extend their analysis by adding business cycle features such as time dependent savings rate. To our knowledge, the fluctuation decomposition is new to the literature.

\footnotetext{
1 We use the terms optimal emission price and Pigouvian emission price interchangeably.

2 A value of the SCC can be derived using general equilibrium environment-economy models, that is, integrated assessment models, with a cost-benefit framework using explicit climate change damages (e.g. Nordhaus 1993, 2008; Hope 2011; Anthoff and Tol 2013; Greenstone et al. 2013)

3 Annicchiarico and Di Dio (2015) and Grodecka and Kuralbayeva (2015) have included non-RBC elements such as nominal rigidities into their DSGE models. Similarly, van den Bijgaart and Smulders (2018) examine with a two-period partial equilibrium model the business cycle implications of financial frictions to carbon pricing. It is not clear, however, whether it is optimal to react with climate policies to such frictions, which could more efficiently be corrected with other policy instruments. Hence, we focus on the firstbest policy in a RBC framework as the additional frictions might complicate the analysis of the business cycle properties of the SCC.
} 
In addition to above mentioned business cycle literature, our paper is also connected to the recent studies about the impact of stochasticity on the SCC. For example, Cai and Lontzek (2019) and van den Bremer and van der Ploeg (2019) show that the economic and climate uncertainty affects the level of the SCC through various mechanisms. However, they do not report business cycle implications of the SCC. Dietz and Stern (2015) examine effects of parameter uncertainty, including growth, in DICE model (Nordhaus and Sztorc 2013), but they do not focus on the SCC but on climate beta, i.e., the ability of climate change mitigation to hedge aggregate consumption risk of future generations. We contribute to this literature by examining how growth shocks, i.e., total factor productivity (TFP) fluctuation, translates into the first-best emissions pricing.

Our key findings are as follows. First, we show that the business cycle properties of the SCC are mostly dictated by those of marginal utility of consumption. This is explained by the vast atmospheric carbon stock and sluggish global mean temperature, which react only weakly to the business cycle variations of emissions. Since the climate damages, measured in utility terms, change only a little, the SCC measured in consumption terms (unit $\mathrm{USD} / \mathrm{CO}_{2}$ ) is shifted by the current valuation of the utility losses, i.e., the inverse of the marginal utility of consumption. This implies strong covariation between the SCC and the final good consumption. Thus, whenever the consumption is procyclical, the SCC is likely to be procyclical. The procylicality of the carbon tax has been found already by (Heutel 2012) and has been obtained in different but related DSGE setups. ${ }^{4}$ Heutel explains the procyclicality of taxes through a need for preventing emissions from overshooting as the abatement is costlier during economic expansion, but he also states that the variance of consumption causes the variance of tax. Our results show that the procyclicality of the SCC is mostly driven by the fluctuations in marginal utility of consumption, indicating a relatively minor magnitude for the SCC fluctuations. Thus, the observed large changes in EU ETS prices do not seem optimal from the first best point of view.

Second, the optimal emissions are not automatically procyclical but the cyclical properties of emissions depend on the production technology of the energy sector. In the model, the technological possibilities are summarized by the elasticity of substitution (EOS) between polluting input and clean capital in the energy generation. ${ }^{5}$ Our numerical results suggest that the emissions are procyclical when the substitutability is low and countercyclical when it is high. Current energy technologies rely largely on fossil fuels which implies low EOS. Instead, the high EOS case describes a possible future energy sector which would rely on renewable energy sources and the fossil fuels would have only a secondary role. The previous DSGE studies have provided strong evidence for the procyclicality of emissions. ${ }^{6}$ This suggests that a procyclical carbon tax cannot change the strong observed

\footnotetext{
4 Annicchiarico and Di Dio (2015) extend the analysis by including New Keynesian elements into the model. They find that tax is procyclical but the response to macroeconomic shocks depends on the level of nominal rigidities and the response of monetary policy. Angelopoulos et al. (2013) find the procyclicality of emission tax in a different setup where government spending is used for abatement. Grodecka and Kuralbayeva (2015) find only weak procyclicality, but their model incorporates additional distortionary taxes (see also Barrage 2020). Finally, van den Bijgaart and Smulders (2018) find that in a partial equilibrium setup, financial shocks with financial frictions can make procyclicality stronger.

5 This approach is comparable to the view taken by Acemoglu et al. (2012) who study the effect of substitutability between polluting and clean inputs on climate change mitigation. In our study the clean input is a capital stock variable whereas in their model the clean input is an unspecified flow variable.

6 In a disaggregated model with fuel switching possibility Dissou and Karnizova (2016) find that coal use may become countercyclical with fixed emission cap.
} 
link between GDP and emissions (Doda 2016, and references therein). These results are based on the model that is calibrated to the current economic and technological conditions. This parallels with our low EOS case. Our results suggest that the high EOS production structure is needed in the energy sector to avoid a climate catastrophe. If such technology would be adopted in the future, emissions might become countercyclical. ${ }^{7}$

Third, we contrast the social optimum with regulations where either the tax or the emission level do not vary over business cycles, but are fixed to their optimal growth path levels. The fixed tax and the optimal carbon price policies result to very similar responses to total factor productivity (TFP) shocks for all the variables irrespective of the production technology of the energy sector. The results with fixed emissions are different in two aspects. First, fixing the emissions results in stronger carbon price responses. Second, the sign of the price response depends on the value of EOS in energy generation. Namely, with the low value of the EOS in fixed emission case the emission price is procyclical whereas with the high value it is countercyclical. Overall, our results suggest that under the business cycle fluctuations of normal magnitude the differences in economic impacts of optimally fluctuating carbon prices and optimally set fixed policies are small. The differences remain relatively small even when the economy faces financial crises that typically cause persistent output losses (Cerra and Saxena 2008). Hence, the first best regulation can be reasonably approximated with a policy that implements an optimal growth path level of carbon price and ignores price fluctuations.

Fourth, since fixed regulation cannot adapt to revealed economic shocks, these results have implications on the prices versus quantities literature (Weitzman 1974): Given the calibration and precisely known gradual climate damages, the fixed tax seems to implement behavior that is close to optimal (e.g. Hoel and Karp 2001, 2002; Newell and Pizer 2003). Instead, the fixed quantity policy seems to distort the economic fluctuations more. However, with the low EOS in energy generation both the SCC and the optimal emissions are procyclical, which implies that, in prices versus quantities setup, the marginal environmental benefit and marginal abatement cost shocks are positively correlated. This improves the welfare properties of a fixed quantity regulation (Stavins 1996). Our results indicate that in the case of low EOS and very persistent shocks the fixed quantity regulation could actually be preferred to a fixed price regulation. Again, the differences in macroeconomic outcomes are small.

Fifth, Newell and Pizer (2008) propose that the tax and emission regulations could be indexed to macroeconomic indicators such as the GDP. Our results suggest that the best indicator for indexing would be the aggregate consumption. The indexing of emission level would be more difficult due to the emissions' strong link with the production technologies.

While our analysis focuses on the cyclical properties of the SCC, our framework is generic, encompassing a variety of environmental pollutants. We find that the time lag between emissions and environmental harm, i.e., the speed of the environmental process, influences the cyclical properties of optimal emission prices. Climate change is a prime example of a slow environmental process, leading to the procyclicality of the Pigouvian tax. The cyclicality of Pigouvian tax of pollutants with fast processes is not as apparent as

\footnotetext{
7 The low substitutability can be associated with the relatively high abatement costs of previous studies (Heutel 2012; Annicchiarico and Di Dio 2015) which result in low level of abatement and procyclical emissions. Instead, with lower abatement costs and higher abatement level, the cyclical properties of emissions may change. This would be consistent with high EOS.
} 
with carbon. However, our results suggest that also with fast emission-environment processes there is a tendency for procyclical Pigouvian taxes.

The rest of paper is organized as follows. Section 2 describes the model framework. Section 3 presents a general formula for the Pigouvian emission price and Sect. 4 analyzes its cyclical properties. In Sect. 5 we calibrate the model to the case of $\mathrm{CO}_{2}$ emissions and present the optimal reaction of the SCC and emissions to a TFP shock. Section 6 discusses the results and 7 concludes.

\section{The Model}

We present a discrete time infinite horizon general equilibrium model, where the economic activity causes an environmental externality. Specifically, we introduce a polluting input use, $X_{t}$, which causes emissions that accumulate into the pollutant stock, $S_{t}$. The pollutant stock contributes to the natural phenomena that are harmful to the society. The strength of these natural phenomena are denoted by $D_{t}$ and we assume that the negative effects of the phenomena arise through a decrease in the total factor productivity. For example, in the climate policy context $X_{t}$ denotes the $\mathrm{CO}_{2}$ emission, $S_{t}$ the aggregate stock of anthropogenic carbon in the atmosphere and $D_{t}$ the temperature change from the preindustrial temperature level.

The economy consists of $N_{t}$ households, each of which consumes the aggregate final good $c_{t}$ and supplies labor, $h_{t}$. The periodic utility of an individual household is

$$
u_{t}=u\left(c_{t}, h_{t}\right),
$$

where consumption has a postitive effect on utility, $u_{c}>0$, whereas labor supply causes disutility, that is, $u_{h}<0$. The utility function, $u$, is concave and households value the future with a common discount factor $\beta$. The aggregate supply of labor is $H_{t}:=N_{t} h_{t}$ and labor input can be used both in the sector producing the final good as well as in the energy sector producing and processing the polluting input. The number of households grows at rate $g_{N}$.

The production of the final good uses labor, $L_{t}$, energy services, $E_{t}$, and capital, $K_{t}^{f i n}$, but is also affected by the environmental conditions $D_{t}$. The production function for the final good is

$$
Y_{t}=F\left(L_{t}, K_{t}^{f i n}, E_{t}, D_{t} ; A_{t}\right) .
$$

Productivity in the final good sector, $A_{t}$, follows an exogenous stochastic process with positive support and variance. Productivity trend $\bar{A}_{t}$ grows at exogenous rate $g_{A}$, i.e., $\bar{A}_{t}=\left(1+g_{A}\right) \bar{A}_{t-1}$. The productivity is an autocorrelated process of the form $A_{t+1} / \bar{A}_{t+1}=\left(A_{t} / \bar{A}_{t}\right)^{\rho_{A}} e^{\varepsilon_{t}}$, where autocorrelation $\rho_{A}>0$ and the innovation $\varepsilon_{t}$ is i.i.d. with Gaussian distribution $N\left(0, \sigma_{\varepsilon}^{2}\right)$.

The energy input, $E_{t}$, describes the energy services used in the final good production and it is generated using polluting input, $X_{t}$, and energy sector capital $K_{t}^{\text {ene }}$,

$$
E_{t}=E\left(X_{t}, K_{t}^{\text {ene }}\right) \text {. }
$$

Similarly to Golosov et al. (2014) we set labor, $\tilde{L}_{t}$, as the sole input in the production of the polluting input. Thus, the remaining labor force, $\tilde{L}_{t}=H_{t}-L_{t}$, is allocated to polluting input production

$$
X_{t}=X\left(\tilde{L}_{t} ; B_{t}\right)
$$


with deterministic productivity variable $B_{t}$, with growth rate $g_{B}$. The production functions (2) and (3) have constant returns to scale and satisfy the Inada conditions. Together with a concave (4) the functional form assumptions ensure interior solutions all times.

While the production structure of the energy sector may seem restrictive, the specification is a rather general two-level nested setup, where the output is based on combination of sector-specific capital and labor. Hence, the energy sector capital needs to be understood very broadly. It encompasses power plants, vehicles, appliances but also equipment used in the production of the polluting input, such as coal mining equipment and oil refineries. The exact composition of the capital depends on the substitutability between capital and polluting input: If they are complements, capital is more strongly linked to the utilization of fossil fuels. If they are substitutes, capital encompasses more technologies that are independent of fossil fuel use. Our choice to link emissions only to the use of labor allows us to model reductions of emission intensity in the sector, while maintaining reasonable business cycle fluctuations in the fossil fuel use.

Both the final good and the energy sector capital stocks are assumed to depreciate with a capital specific constant rate $\delta_{i}$, where $i \in\{$ fin, ene $\}$. The dynamics of the capital stocks is standard

$$
K_{t+1}^{i}=\left(1-\delta_{i}\right) K_{t}^{i}+I_{t}^{i} .
$$

As we analyze a closed economy, the sum of investments $I_{t}^{i}$ is equal to the savings, i.e.

$$
I_{t}^{f i n}+I_{t}^{e n e}=Y_{t}-C_{t},
$$

where the aggregate consumption $C_{t}=c_{t} N_{t}$, i.e., the sum of consumption by all the households.

The link between the emissions, $X_{t}$, the pollutant stock, $S_{t}$, and the environmental harm variable, $D_{t}$, forms a dynamical system that determines a correspondence between current emissions, $X_{t}$ and future environmental harm, $D_{t+s}$. An emission pulse can decay in a complicated manner, depiction of which may require several geometrically decaying pollutant stocks. A share $\varepsilon_{i}$ of emissions, $X_{t}$, contributes to a pollutant stock $S_{i t}$ that develops as

$$
S_{i, t}=\left(1-\sigma_{i}\right) S_{i, t-1}+\varepsilon_{i} X_{t} .
$$

We assume that $\sigma_{i} \in[0,1]$ and $\sum_{i} \varepsilon_{i}=1$.

The sum of pollutant stocks, $S_{t}=\sum_{i} S_{i t}$, imposes forcing, $\Phi\left(S_{t}\right)$, on the development of the environmental harm, $D_{t+1}$. Also the environmental harm can react to pollutant forcing in a complicated way and, therefore, it may need to be split into several variables, $D_{j t}$, so that $D_{t}=\sum_{j} D_{j t}$. Development of environmental harm state variables is given by

$$
D_{j, t+1}=\left(1-\eta_{j}\right) D_{j t}+\lambda_{j} \Phi\left(S_{t}\right) .
$$

To assess a general case of pollutants and environmental harm, we depict this correspondence with a function $D_{t}=D\left(\chi_{t}\right)$, which aggregates the effects of past emissions $\chi_{t}=\left(X_{t-1}, X_{t-2}, \ldots\right)$ on the current environmental harm, $D_{t^{*}}{ }^{8}$ The marginal effects of

\footnotetext{
${ }^{8}$ These lagged input uses could be linked to the nonrenewable resource stocks but this is an option we do not use here. Instead we assume that fossil fuels are abundant and yield zero Hotelling rents (cf. Golosov et al. 2014).
} 
emissions on environmental harm $s$ periods later are directly obtained through partial derivatives

$$
\omega_{t s}:=\frac{\partial D_{t+s}}{\partial X_{t}}=\sum_{u=0}^{s-1} \xi_{s u} \Phi^{\prime}\left(S_{t+u}\right),
$$

where (Appendix 1)

$$
\xi_{s u}:=\sum_{i} \varepsilon_{i}\left(1-\sigma_{i}\right)^{u} \sum_{j} \lambda_{j}\left(1-\eta_{j}\right)^{s-u-1}
$$

The marginal effect of emissions propagates to changes in environmental harm through the marginal forcing by the pollutant stock $\Phi^{\prime}\left(S_{t+u}\right)$. Since the emission can cause a longlasting pulse to the pollutant stock (7) and the stock level can cause persistent environmental harm (8), the emission-harm link can be complicated (9) and (10). In line with Gerlagh and Liski (2018b), the analysis of an environmental system can be performed with the lagstructure of the partial derivatives, $\omega_{t}=\left(\omega_{t 1}, \omega_{t 2}, \ldots\right)$. The properties of $\omega_{t}$ are determined by the dynamical system between emissions, pollution stocks and environmental harm, that is, by forcing function $\Phi\left(S_{t}\right)$ and parameters $\varepsilon_{i}, \sigma_{i}, \lambda_{j}$, and $\eta_{j}$.

To cut emissions the economy needs to reduce the use of polluting input by substituting energy capital for polluting input use in energy production (3), substituting other inputs for energy service use in final good production (2), and reducing output. This parallels with recent literature (Acemoglu et al. 2012; Golosov et al. 2014; Gerlagh and Liski 2018b). The emission reduction costs depend on the substitutability (i) between polluting input and energy capital in energy generation, and (ii) between energy services and other inputs in the final good production. In the quantitative assessment (Sect. 5), we focus on the case (i) and examine the effect of the elasticity of substitution (EOS) between polluting input and energy capital on the business cycle properties of the optimal policy.

\section{The Optimal Emission Price}

\subsection{Planning Solution}

The social planner maximizes the net present value of utility and the problem can be presented as a dynamic program, where the value function $V$ is determined through optimization problem

$$
\begin{aligned}
& V\left(K_{t}^{f i n}, K_{t}^{\text {ene }}, A_{t}, \chi_{t}, N_{t}\right) \\
& \quad=\max _{\left\{H_{t}, L_{t}, t_{t}^{\text {fin }}, I_{t}^{\text {ene }}\right\}} N_{t} u\left(C_{t} / N_{t}, H_{t} / N_{t}\right)+\beta \mathbb{E}_{t} V\left(K_{t+1}^{f i n}, K_{t+1}^{\text {ene }}, A_{t+1}, \chi_{t+1}, N_{t+1}\right)
\end{aligned}
$$

subject to constraints given by the Eqs. (2)-(9). Since labor supply and labor use in final good production uniquely determine the polluting input use, and the saving decision determines the level of consumption, the optimization is performed through labor supply, $H_{t}$, labor use in final good sector, $L_{t}$, and the investment variables, $\boldsymbol{I}_{t}$. Solving the optimization problem (see Supplement S.1) yields the standard Euler equations for consumption smoothing 


$$
\begin{gathered}
u_{c t}=\beta \mathbb{E}_{t}\left[\left(1-\delta_{f i n}+F_{K, t+1}\right) u_{c, t+1}\right], \\
u_{c t}=\beta \mathbb{E}_{t}\left[\left(1-\delta_{\text {ene }}+F_{E, t+1} E_{K, t+1}\right) u_{c, t+1}\right],
\end{gathered}
$$

the labor supply condition

$$
F_{L t} u_{c t}+u_{h t}=0
$$

and

$$
F_{L t} u_{c t}=\left\{F_{E t} E_{X t} u_{c t}+\mathbb{E}_{t} \sum_{s=1}^{\infty} \beta^{s} \omega_{t s} u_{c, t+s} F_{D, t+s}\right\} X_{\tilde{L} t},
$$

which pins down the optimal allocation of labor between final good and energy sectors. The LHS of Eq. (15) represents the marginal product of labor in the final good sector and the RHS the marginal product of labor in the polluting input production, both measured in utility terms. The first term in the braces is the value of the input use in the energy sector and the second term represents the net present value of the marginal environmental harm $\left(F_{D}<0\right)$ generated by the input use in energy sector. To compensate this detriment, the marginal productivity of labor in polluting input production has to be larger than in the final good production $\left(F_{E} E_{X} X_{\tilde{L}}>F_{L}\right)$.

The solution of the planning problem describes a market equilibrium, where households decide their labor supply and investments in final good and energy capital. In addition, representative firms in three different sectors (final good, energy services, and polluting input) maximize their profits. The firms that produce energy services, are levied an emission tax, value of which is equal to the social cost of carbon. Details of the market equilibrium are presented in the Supplement S.2.

\subsection{The Pigouvian Emission Price}

Given the model structure presented in Sect. 2, we can derive an expression for the Pigouvian emission price that will enforce the first-best outcome in a decentralized economy:

Proposition 1 The optimal emission price, $\tau_{t}$, is

$$
\tau_{t}=-u_{c t}^{-1} \mathbb{E}_{t} \sum_{s=1}^{\infty} \beta^{s} \omega_{t s} u_{c, t+s} F_{D, t+s},
$$

where $\omega_{t}$ denotes the lag-structure between emissions and environmental harm defined in Eq. (9).

Proof The optimal emission price is derived using the decentralized solution of the model presented in Sect. 2. In the decentralized setup, the energy sector is regulated with a timedependent Pigouvian emission payment, $\tau_{t}$ (Supplement S.2). The profit maximization condition of the energy sector is $p_{t} E_{X t}=q_{t}+\tau_{t}$, where $p_{t}$ is the price of energy services, $q_{t}$ the price of polluting input and $E_{X t}$ the marginal product of polluting input. In the equilibrium $p_{t}=F_{E t}$ and the wages in final good and polluting input sectors are equal, i.e., $F_{L t}=q_{t} X_{\tilde{L} t}$. These conditions lead to labor allocation equilibrium condition 


$$
F_{L t}=\left[F_{E t} E_{X t}-\tau_{t}\right] X_{\tilde{L} t}
$$

The direct comparison between (15) and (17) leads to Eq. (16). Since there is only one externality and there are no informational restrictions, the Pigouvian emission payment enforces the first-best optimum.

The Pigouvian emission price (16) is composed of two factors. The first factor, $u_{c t}^{-1}$, is the inverse of marginal utility of consumption and the second term is a sum factor that denotes the expected net present value of marginal harm caused by the emission. The marginal environmental harm results from production losses that are depicted by the term $u_{c, t+s} F_{D, t+s}$ in Eq. (16). The lag-structure of the propagation of emissions into environmental harm over time is denoted by $\omega_{t s}$ (see Eq. (9)). Jointly with the discount factor, $\beta$, the lag-structure determines the relative contributions of different time lags, $s$, to the current emission price level, $\tau_{t}$.

The optimal emission price formula (16) is general and it is not restricted to the carbon emissions but it encompasses all the pollutants which can have macroeconomic effects. It is analogous to ones derived in the climate change literature for the social cost of carbon (e.g. Golosov et al. 2014; van den Bijgaart et al. 2016; Gerlagh and Liski 2018a, b). In these papers, the SCC formula has been reformulated in a way that the SCC is purely driven by the production level. This happens either because the model assumptions enforce constant savings rate (Golosov et al. 2014; Gerlagh and Liski 2018a, b) or they focus on deterministic growth path (van den Bijgaart et al. 2016). Neither assumption is appropriate for the analysis of short-term economic fluctuations that is our focus. Therefore, we do not pursue this line of modeling but use a business cycle model that has fluctuating savings rate.

\section{The Fluctuations of the Optimal Emission Price}

\subsection{Fluctuations Around a Growth Path}

Next we examine the business cycle fluctuations of the optimal emission price through relative deviations around an arbitrary growth path. ${ }^{9}$ Let's denote the growth path values of variables by an overhead bar. On the growth path, the marginal damage terms of Eq. (16) develop as $\bar{u}_{c, t+s} \bar{F}_{D, t+s}=\bar{u}_{c t} \bar{F}_{D t} \prod_{u=0}^{s-1}\left(1+g_{t+u}\right)$, where $g_{t+u}$ is the growth rate of marginal damages in period $t+u$ on the growth path. We denote $\prod_{u=0}^{s-1}\left(1+g_{t+u}\right)=G_{t s}$. On this growth path, the optimal emission price (16) can be written as

$$
\bar{\tau}_{t}:=\left|\bar{F}_{D t}\right| \sum_{s=1}^{\infty} \beta^{s} \bar{\omega}_{t s} G_{t s} .
$$

Thus, the growth path Pigouvian tax, $\bar{\tau}_{t}$, can be written as the absolute value of current marginal damage $\left|\bar{F}_{D t}\right|$ multiplied by a sum term $\sum_{s=1}^{\infty} \beta^{s} \bar{\omega}_{t s} G_{t s}$. The sum term aggregates the present value of the prolonged change in environmental harm caused by the current emission, $\bar{\omega}_{t s}$, given the growth of the marginal damages (in utility terms), $G_{t s}$.

\footnotetext{
9 The growth path studied here is not necessarily a balanced growth path. In fact, the model presented in Sect. 2 has only a restricted set of balanced growth paths (see Sect. 5.1).
} 
We decompose the realization of the optimal emission price into the growth path value (18) and the deviation around it. The formal representation of the proportional fluctuations can be obtained:

Proposition 2 The relative deviation of the optimal emission price around the growth path is

$$
\hat{\tau}_{t}=-\hat{u}_{c t}+\sum_{s=1}^{\infty} w_{t s} \mathbb{E}_{t}\left[\hat{\omega}_{t s}+\hat{u}_{c, t+s}+\hat{F}_{D, t+s}\right],
$$

where hat denotes proportional change from the growth path, for example, $\hat{\tau}_{t}:=d \tau_{t} / \bar{\tau}_{t}$. The factor $w_{t s}$ is a weight indicating the time-lag of harmful effects and it is defined by ${ }^{10}$

$$
w_{t s}:=\frac{\beta^{s} \bar{\omega}_{t s} G_{t s}}{\sum_{u=1}^{\infty} \beta^{u} \bar{\omega}_{t u} G_{t u}} .
$$

Proof The presentation follows directly from log-linearization of the Pigouvian emission tax (16) around the deterministic growth path, $\bar{\tau}_{t}$.

The proposition states that fluctuations of the optimal emission price are driven by the fluctuations of current marginal utility plus the weighted average of expected future fluctuations of emission-harm linkage, $\omega_{t s}$, marginal utility of consumption, $u_{c, t+s}$, and marginal damages, $F_{D, t+s}$. The weights, $w_{t s}$, used in averaging depend on the discount factor, $\beta$, emission to harm process, $\bar{\omega}_{t s}$, and the growth of marginal damages in utility terms, $G_{t s}$.

The log-linearization provides us a convenient tool to analyze the business cycle properties of an emission price: Emission price $\hat{\tau}_{t}$ is procyclical if it correlates positively with the production level, $\hat{Y}_{t}$ (Prescott 1986). To examine the cyclical properties of the Pigouvian tax, two assumptions are made:

Assumption 1 The per capita consumption, $c_{t}$, and labor supply, $h_{t}$, are additively separable in the utility function $u\left(c_{t}, h_{t}\right)$.

Assumption 2 The environmental damages are multiplicatively separable in the production function, i.e. $Y_{t}=F\left(L_{t}, X_{t}, K_{t}, D_{t} ; A_{t}\right)=\Delta\left(D_{t}\right) \Phi\left(L_{t}, X_{t}, K_{t} ; A_{t}\right)$.

Assumption 1 simplifies the presentation as labor supply decision is not affecting the marginal utility of consumption. Assumption 2 restricts the connection between the environmental harm and the production capacity of the economy and is widely applied in economic literature (e.g. Nordhaus 1993; Golosov et al. 2014). With this formulation, marginal production loss due to environmental harm is multiplicative, $F_{D}(\cdot)=\Psi\left(D_{t}\right) F(\cdot)$, where $\Psi\left(D_{t}\right):=\Delta^{\prime}\left(D_{t}\right) / \Delta\left(D_{t}\right)$. As a result, the relative change of marginal production loss is a sum $\hat{F}_{D}=\hat{\Psi}+\hat{F}$.

Under Assumptions 1 and 2, we can rewrite the price fluctuation Eq. (19) in the terms of percentage deviations of variables from their growth path values as

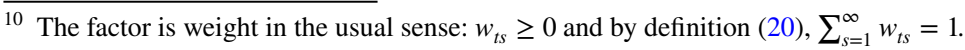




$$
\hat{\tau}_{t}=\left|\varepsilon_{u_{c} c}\right| \hat{c}_{t}+\sum_{s=1}^{\infty} w_{t s} \mathbb{E}_{t}\left[\hat{Y}_{t+s}-\left|\varepsilon_{u_{c} c}\right| \hat{c}_{t+s}+\hat{\omega}_{t s}+\varepsilon_{\Psi D} \hat{D}_{t+s}\right]
$$

\section{Corollary 1}

where $\varepsilon_{\varphi z}:=z \varphi^{-1} \varphi_{z}$ denotes the elasticity of a function $\varphi(z)$ with respect to a variable $z .{ }^{11}$

Proof The formulation follows directly from Proposition 2 (Eq. (19)) when applying Assumptions 1-2 and noting that for a differentiable function $\varphi(z), \hat{\varphi}=\varepsilon_{\varphi z} \hat{z}$.

The first term is the deviation of present marginal utility of consumption. The sum term represents the weighted average of expected changes in the future damages by the environmental harm. It consists of four terms. The first two denote changes in economic factors: the production level and the marginal utility of consumption. The latter two are changes in environmental factors: the propagation of emissions into environmental harm and the marginal production losses. ${ }^{12}$ Since the utility and production functions are concave, the elasticity $\varepsilon_{u_{c} c}$ is negative (hence the absolute value in Eq. (21)) and elasticity $\varepsilon_{{ }_{\Psi D}}$ is positive.

The relative importance of the terms in Eq. (21) is dependent on three factors: The magnitude of related elasticity $\left(\varepsilon_{u_{c} c}\right.$ and $\left.\varepsilon_{\Psi D}\right)$, the strength of the related response, $\hat{z}_{t+s}$, and, in the case of expected future values, the level of co-variation between the lag-weights, $w_{t s}$, and the response $\hat{z}_{t+s}$ in question. The first two factors are rather straightforward, but the last factor deserves further explanation. The effect of future fluctuations on current emission price is determined through a weighted mean, that is, an infinite sum of products $w_{t s} \hat{z}_{t+s}$, where $z$ is the variable in question. ${ }^{13}$ Naturally, the weighted mean has the greater absolute value the greater the weights, $w_{t s}$, for large values of examined variable, $\hat{z}_{t+s}$, are. If the match between weights and responses is poor, the weighted average term will have a small value and a weak impact on the variation of the optimal emission price.

To illustrate the role of emission-harm-linkage we analyze the Eq. (21) further. The relative effects of each term in the equation depends on the specifics of the studied pollutant. Especially, the effects depend on the timescale in which the emissions are propagated into environmental harm. Next we will analyze the case of a slow environmental process such as carbon emissions and climate change. The case of a fast environmental process is analyzed in Appendix 2.

\subsection{The Case of Slow Environmental Process}

Environmental process is slow, when the pollutant is long-lived and the propagation of emissions into environmental harm is slow. For slow processes, such as climate change, the emission-damage lag-structure, $\omega_{t s}$, peaks only after a couple of decades and it takes centuries for it to decay to zero. To analyze the cyclical properties of the optimal emission price (21) we assume that there is a positive deviation in the production level at period $t, \hat{Y}_{t}>0$, for example due to a positive productivity shock, and assess the resulting deviation in the emission price level. Of course, the exact equilibrium reactions of the examined variables

\footnotetext{
11 In Eq. (21), we have used the fact that $D_{t}$ cannot change instantly but there is a lag of at least one period.

12 The propagation term, $\hat{\omega}_{t s}$, would vanish, in the case of linear emission-damage link (e.g. Heutel 2012; Golosov et al. 2014; Annicchiarico and Di Dio 2015; Gerlagh and Liski 2018b).

13 We make here a rather safe assumption that the elasticities are relatively constant over the business cycle.
} 
depend on the specific shocks driving the economic fluctuations. Our analysis abstracts this and, therefore, we discuss four possible cases of equilibrium outcomes.

The emission price fluctuations (21) consists of five terms, which we group into three: marginal utility of consumption, economic terms, and environmental terms. Table 1 shows whether these three terms are pro- or countercyclical, ' + ' or '-' signs, respectively. If the sign is in parenthesis, the term is considered small relative to the terms without parenthesis. The column "MU" presents the current period marginal utility of consumption, $\left|\varepsilon_{u_{c} c}\right| \hat{c}_{t}$, which is in most situations positively correlated with aggregate production, i.e., procyclical. The columns "Econ." and "Env." present the terms with economic variables and the terms related to the environmental processes, respectively. Their cyclical properties are case dependent.

The economic terms, $\hat{Y}_{t+s}-\left|\varepsilon_{u_{c} c}\right| \hat{c}_{t+s}$, measure the value of marginal production change in utility terms. The joint effect of these terms on the Pigouvian emission price can be either pro- or countercyclical, cases $1-2$ and 3-4, respectively. ${ }^{14}$ Since the economic variables $Y_{t}$ and $c_{t}$ tend to fluctuate with shorter time-scales (years/decades) than the slow environmental process (decades/centuries) the match between the economic fluctuations and the lag-weights $w_{t s}$ is poor. Therefore, the weighted average in column "Econ." is likely to be quite small. As a result the effect of economic variables on the optimal emission price are small in relative terms, as indicated by the parenthesis around response signs in Table 1.

The "Env." column of Table 6 depicts the terms that are related to the emissions-toharm process, $\hat{\omega}_{t 1}$, and to the environmental harm, $\hat{D}_{t+1}$. The driver here is the correlation of emission level, $\hat{X}_{t}$, with the production level $\hat{Y}_{t}$. The propagation process, $\hat{\omega}_{t}$, reacts directly to the development in emission level. Using Eqs. (9) and (10), we can write

$$
\hat{\omega}_{t s}=\sum_{u=0}^{s-1} \frac{\xi_{s u} \Phi^{\prime}\left(S_{t+u}\right)}{\omega_{t s}} \varepsilon_{\Phi^{\prime} S} \hat{S}_{t+u} .
$$

The environmental forcing $\Phi$ can be convex or concave and, therefore, elasticity $\varepsilon_{\Phi^{\prime} S}$ can be positive or negative, respectively. Thus, term's impact can be either way, depending on the environmental phenomenon in question and is case dependent. Together with the case dependent economic terms we have in total four different cases reported in Table 1. The environmental damage, $\varepsilon_{\Psi D} \hat{D}_{t+1}$, is more straightforward to analyze. By convex damages assumption, the elasticity $\varepsilon_{\Psi D}$ is positive. Since higher emissions increase environmental harm, response $\hat{D}_{t+1}$ follows the response of emissions.

The magnitude of the environmental effects (column "Env.") is affected by two contradicting features. First, the weights $w_{t s}$ are, in part, dictated by $\bar{\omega}(20)$ and therefore they get significant values in similar time scales as the fluctuations of the environmental variables of the model $\left(\hat{S}_{t}\right.$ and $\left.\hat{D}_{t}\right)$. This enhances the impact of these terms on the Pigouvian price fluctuations. Second, under slow environmental processes the state of the environment is determined by the centuries of emission history. Therefore, small fluctuations in current emissions contribute only little to the future carbon stock $S_{t+s}$. As a result, the relative changes $\hat{\omega}_{t s}$ and $\hat{D}_{t+s}$ are small in magnitude which weakens the impact of these terms on

\footnotetext{
14 Although, the initial pro-cyclical response of $Y_{t}$ is typically greater than that of $c_{t}$, the consumption response is more long-lasting. With a slow environmental process, the lag-weights $w_{t s}$ get significant values only after several years. Therefore, the relative role of the consumption term is enhanced, which increases the countercyclical contribution of the term.
} 
Table 1 Cyclicality of terms contributing to the cyclicality of the Pigouvian emission price (Eq. (21))

\begin{tabular}{lllll}
\hline & MU & Econ. & Env. & Price \\
& $\left|\varepsilon_{u_{c} c}\right| \hat{c}_{t}$ & $\sum_{s} w_{t s}\left(\hat{Y}_{t+s}-\left|\varepsilon_{u_{c} c}\right| \hat{c}_{t+s}\right)$ & $\sum_{s} w_{t s}\left(\hat{\omega}_{t s}+\varepsilon_{\Psi D} \hat{D}_{t+s}\right)$ & $\hat{\tau}_{t}$ \\
\hline Case 1 & + & $(+)$ & $(+) /+$ & + \\
Case 2 & + & $(+)$ & $(-) /-$ & $+/ ?$ \\
Case 3 & + & $(-)$ & $(+) /+$ & + \\
Case 4 & + & $(-)$ & $(-) /-$ & $+/ ?$ \\
\hline
\end{tabular}

'+' sign indicates procyclicality and '-' sign countercyclicality of the corresponding term. Response signs in parenthesis denote a supposed small impact which does not overcome effects without parenthesis. Last column shows the resulting cyclicality of the Pigouvian price, $\hat{\tau}_{t}$

the Pigouvian price fluctuations. This is indicated by the parenthesis around response signs in Table 1.

However, if the economy is close to an environmental catastrophe, that is, on a brink of an environmental tipping point (e.g. Lemoine and Traeger 2014; Lontzek et al. 2015; Cai and Lontzek 2019), the damage elasticity, $\varepsilon_{\Psi D}$, may be large. This increases the effect of these terms on the cyclical properties of the Pigouvian price (hence the signs without parenthesis in column "Env." of Table 1).

Overall, our main result is that in the case of slow environmental process, the changes in Pigouvian emission prices over the business cycle are likely driven by the current marginal utility of consumption, $\left|\varepsilon_{u_{c} c}\right| \hat{c}_{t}$. Due to the concavity of utility, the increase in consumption during booms lowers the marginal utility losses caused by the emission price and, therefore, the households are ready to pay higher emission prices in consumption terms. As the marginal environmental damages in utility terms remain roughly constant, the emission price needs to be increased in economic boom to maintain a correct price signal. An only notable exception is the case of catastrophic environmental harm, with a very large elasticity $\varepsilon_{\Psi D}$, where even a slight deviation in $D$ can affect the price fluctuations. In that case the cyclical tendencies follow those of the emissions. If the emissions are countercyclical and the environmental effects strong enough, they can overcome procyclical effects of the present marginal utility of consumption (cases 2 and 4). Since under a long-lasting pollution and a slow environmental process the relative changes in $D$ are in all likelihood very modest, the countercyclicality of an optimal emission price seems unlikely.

\section{Quantitative Assessment of $\mathrm{CO}_{2}$ Emissions}

\subsection{Calibration}

Climate change due to anthropogenic carbon dioxide emissions is a prime example of a slow environmental process: The atmospheric life-time of $\mathrm{CO}_{2}$ is long as a fraction of an emission is effectively airborne after thousands of years (Archer 2005). In addition, the temperature response to radiative forcing caused by the $\mathrm{CO}_{2}$ stock is slow and long-lasting. Our numerical specification focuses on the cyclical properties of an optimal carbon price, i.e., the social cost of carbon (Pearce 2003). Thus, the emissions, $X_{t}$, denote $\mathrm{CO}_{2}$ emissions 
contributing to the atmospheric stock of $\mathrm{CO}_{2}$ of anthropogenic origin, $S_{t}{ }^{15}$ We assume that the harmful effects of the global warming are uniquely linked to the temperature increase from the pre-industrial temperature level, $D_{t}$, which is measured in degree Celsius, ${ }^{\circ} \mathrm{C}$.

As shown in Sect. 4, the SCC is affected by the dynamics of the climate system, that is, the lag-structure between emissions and resulting temperature change. The lag-structure depends both on the decay profile of atmospheric carbon and the temperature response to a change in the radiative forcing of the atmospheric carbon. The climate science suggests that the carbon decay and temperature response have complicated time-paths and cannot be presented with single state variable (e.g. Joos et al. 2013; Boucher and Reddy 2008). To accommodate this, we apply processes with three and two state variables for the atmospheric carbon and global temperature, respectively. These state variables ("boxes") do not have useful interpretations, but provide realistic representation for the decay processes (Appendix 1).

The development of atmospheric $\mathrm{CO}_{2}$ stock in box $i$ follows an equation

$$
S_{i t}=\left(1-\frac{1}{4 T_{i}^{S}}\right) S_{i, t-1}+\varepsilon_{i} X_{t} .
$$

The parameter $\varepsilon_{i}$ denotes the share of emissions contributing to the box $i$ and the quarterly decay rate in box $i$ is given by $1 /\left(4 T_{i}^{S}\right)$, where $T_{i}^{S}$ denotes the decay time-scale in years. The total anthropogenic atmospheric $\mathrm{CO}_{2}$ stock is the sum of the stocks in the three boxes, that is, $S_{t}=\sum_{i} S_{i t}$.

For the temperature change, we specified a non-linear two-box model. The temperature change in the box $j$, is given by

$$
D_{j, t+1}=D_{j t}+\frac{1}{4 T_{i}^{D}}\left(\pi_{j} \frac{\log \left(1+S_{t} / S_{p r e}\right)}{\log 2}-D_{j t}\right)
$$

with relaxation time-scale $T_{i}^{D}$ and the total temperature change is the sum $D_{t}=D_{1 t}+D_{2 t}$. The logarithmic relation for radiative forcing by $\mathrm{CO}_{2}$ is a standard formulation (Wigley 1987; Shine et al. 1990). The doubling of the concentration of atmospheric carbon from its preindustrial level, $S_{\text {pre }}=2.13 \mathrm{Tt}_{\mathrm{CO}_{2}}$, increases the steady-state temperature by $\pi_{1}+\pi_{2}$, which is called climate sensitivity. The climate sensitivity gives the scale of the temperature response to the changes in atmospheric carbon stock.

Table 2 summarizes the climate parameters used in this study. The values are adapted from Joos et al. (2013) and Boucher and Reddy (2008). We made two changes. First, we approximate the non-stationary carbon model of Joos et al. (2013) with a stationary one by combining their two slowest boxes ${ }^{16}$ by one box with 800 years decay time-scale. The approximation is sufficient for several hundred years and allows quantitative assessment of the model along a balanced growth path (BGP). Second, for the climate sensitivity we assumed a value of $3{ }^{\circ} \mathrm{C}$, instead of $3.9^{\circ} \mathrm{C}$ of Boucher and Reddy (2008). The climate sensitivity of $3{ }^{\circ} \mathrm{C}$ is the mean value of the range of estimates given by IPCC (2013) and provides better comparability with other economic models (e.g Nordhaus and Sztorc 2013; Gerlagh and Liski 2018b).

\footnotetext{
15 The anthropogenic carbon stock is additional to the natural, that is, pre-industrial level of atmospheric carbon.

${ }^{16}$ Decay time-scales of 394.4 and infinite years. See Supplement S.3 for details.
} 
The final good is produced via the Cobb-Douglas technology with labor, capital and energy services as inputs, $L_{t}, K_{t}^{f i n}$ and $E_{t}$, respectively. The temperature deviation, $D_{t}$, decreases the productivity in a multiplicative manner through a function $\Delta\left(D_{t}\right)$. The global production function is

$$
F\left(L_{t}, K_{t}^{f i n}, E_{t}, D_{t} ; A_{t}\right)=\Delta\left(D_{t}\right) A_{t}\left(\frac{L_{t}}{L_{0}}\right)^{\alpha_{L}}\left(\frac{K_{t}^{f i n}}{K_{0}^{f i n}}\right)^{\alpha_{K}}\left(\frac{E_{t}}{E_{0}}\right)^{1-\alpha_{L}-\alpha_{K}},
$$

where $A$ is the exogenous stochastic total factor productivity (TFP) variable. The initial levels of labor, capital and energy services are presented by $L_{0}, K_{0}^{f i n}$ and $E_{0}$, respectively. As usual, the parameters $\alpha_{L}$ and $\alpha_{K}$ are the cost shares of labor and capital in final good production. The production losses due to climate change are presented by a concave function

$$
\Delta\left(D_{t}\right):=1-\left(D_{t} / \Delta_{y}\right)^{1+\xi},
$$

where $\Delta_{y}$ and $\xi$ are the temperature scale and elasticity parameters. Our parameter values $\Delta_{y}=19.35^{\circ} \mathrm{C}$ and $\xi=1$ equalizes the damage function with the one in DICE 2013R (Nordhaus 2014; Nordhaus and Sztorc 2013). The parametrization, together with climate sensitivity of $3{ }^{\circ} \mathrm{C}$, implies $2.4 \%$ decrease in production level from a doubling of atmospheric carbon compared to preindustrial level. This is comparable to previous economic assessments (e.g Gerlagh and Liski 2018b).

The energy services are produced by polluting inputs, such as fossil fuels, $X_{t}$, and nonpolluting energy capital $K_{t}^{\text {ene }}$. These inputs are aggregated through a CES specification:

$$
E\left(X_{t}, K_{t}^{\text {ene }}\right)=E_{0}\left[\mu\left(\frac{X_{t}}{X_{0}}\right)^{\frac{\gamma-1}{\gamma}}+(1-\mu)\left(\frac{K_{t}^{\text {ene }}}{K_{0}^{\text {ene }}}\right)^{\frac{\gamma-1}{\gamma}}\right]^{\frac{\gamma}{\gamma-1}} .
$$

The parameter $E_{0}$ sets the scale at calibration point and $X_{0}$ and $K_{0}$ are the initial values of polluting input use and energy capital, respectively. ${ }^{17}$ The parameter $\mu \in(0,1)$ is the weight of polluting input in energy production and $\gamma$ is the elasticity of substitution (EOS) between the two inputs. The polluting input, $X_{t}$ is produced with a linear production function, which has labor, $\tilde{L}_{t}$, as a sole input:

$$
X\left(\tilde{L}_{t}\right)=B_{t} \tilde{L}_{t}
$$

Here, $B_{t}$ is an exogenous deterministic productivity variable. Similarly to Golosov et al. (2014), the supply of polluting input is infinite implying zero Hotelling rents.

The energy production captures the main avenue for emission abatement, i.e., replacing polluting input with energy production capital. If the elasticity of substitution $\gamma$ is low in Eq. (27), the energy sector capital is strongly linked to polluting input use, and the abatement is expensive. In the case of high $\gamma$, the abatement is less expensive because the capital encompasses clean technologies, such as wind turbines, photovoltaics and nuclear power. ${ }^{18}$

\footnotetext{
17 We do not need to specify the value of $E_{0}$ as it is canceled in the production function of final good (25).

18 Even in the high EOS case the CES-specification requires positive use of polluting input. This can be motivated through the energy service logic: The production levels of photovoltaics and wind turbines vary randomly and to match the production with the demand the energy sector uses polluting input to provide this regulatory service.
} 
Table 2 Parameters of the climate model

\begin{tabular}{llll}
\hline$\varepsilon_{i}$ & $T_{i}^{S}$ (years) & $\pi_{j}\left({ }^{\circ} \mathrm{C}\right)$ & $T_{j}^{D}$ (years) \\
\hline 0.2763 & 4.304 & 1.786 & 8.4 \\
0.2824 & 36.54 & 1.214 & 409.5 \\
0.4413 & 800 & & \\
\hline
\end{tabular}

Since the EOS, $\gamma$, has a strong impact on abatement costs, in the quantitative assessment we examine how does its level affect the fluctuations of both the SCC and the optimal emissions. We focus on parameter levels $\gamma \in\{1,4,7\}$.

Our calibration suggests that $\gamma=1$ is reasonably close to the current energy sector technology. The simulated correlation between emissions and the GDP in a no-policy market solution is 0.78 , which is very close to our empirical estimate 0.79 . In addition, it is comparable with the current technology calibration by Heutel (2012). Also the correlations between GDP and energy use, energy use and emissions, and GDP and energy sector labor input are of similar magnitude. ${ }^{19}$ Correlations are reasonably realistic given that we simulate only TFP shocks and do not introduce New Keynesian elements such as nominal rigidities or investment adjustment costs. In the case of possible future energy sector technology $(\gamma=4$ or $\gamma=7$ ), the correlations cannot be tested against empirical observations. However, from global temperature change point of view the $\gamma=7$ case describes a technology that is consistent with $1.5^{\circ} \mathrm{C}$ climate policy target of the Paris Agreement (UNFCCC 2015). The value $\gamma=4$ provides an intermediate case. Hence, we see that the examined range of EOS values seems justifiable for the present illustration.

The utility function is additively separable between final good consumption, $c_{t}$, and the disutility from lost leisure due to labor supply, $h_{t}$,

$$
u\left(c_{t}, h_{t}\right)=\frac{c_{t}^{1-1 / \chi}-1}{1-1 / \chi}-\kappa \frac{h_{t}^{1+1 / \nu}}{1+1 / \nu} .
$$

Parameter $\chi$ is the elasticity of intertemporal substitution (EIS), $v$ is the Frisch elasticity of labor supply and $\kappa$ is the scale of labor disutility. ${ }^{20}$ Annual discount rate is $1.5 \%$, which implies quarterly discount factor $\beta=0.9963$. This choice coincides with the base value used for example in DICE2013R (Nordhaus and Sztorc 2013). ${ }^{21}$

\footnotetext{
19 We calculated empirical correlations from annual time series for years 1986-2017 with the data from BP Statistical review of World Energy, U.S. Bureau of Labor Statistics and the World Bank. The empirical correlations were calculated for business cycle components, i.e., the trend components of time-series were removed using Hodrick-Prescott filter (Hodrick and Prescott 1997; Ravn and Uhlig 2002). The correlations of model variables were calculated from simulated fluctuations around the balanced growth path using Monte Carlo random draws (Adjemian et al. 2011). Empirical correlations between GDP and energy use (in energy units) were 0.81 , and between emissions and energy use (in energy units) 0.98 , whereas simulated correlations from our model were 0.78 and 1 , respectively, when using polluting input use $X_{t}$ for corresponding energy variable. The same correlations for our energy service aggregate, $E_{t}$, were 0.98 and 0.65 , respectively. Unfortunately, we did not have global energy sector labor data available. However, empirical correlation between global GDP and US energy sector labor were 0.44 , whereas our simulated one for global GDP and energy sector labor was 0.78 .

${ }^{20}$ Parameter $\kappa$ is calibrated to yield one unit of labor supply in the calibration point without policy intervention.

21 Much lower discount rates have been proposed. For example, Stern (2007) sets the annual discount factor to $0.1 \%$. The discount rate has a notable effect on the levels of social cost of carbon. However, our
} 
We examine the business cycle fluctuations around a balanced growth path (BGP), where labor force increases at rate $g_{N}$, productivity parameter $A_{t}$ increases at rate $g_{A}$ and the economic activity grows at rate $g_{Y}=g_{A}+g_{N}$. For a model presented above, the BGP sets restrictions on feasible specification. For example, BGP requires a time-invariant atmospheric carbon stock and, hence, constant emissions at the BGP. Different specifications could be envisaged, but the one we considered most reasonable has polluting input use increasing at the rate $g_{Y}$. To keep emissions time-invariant, the one-to-one link between input use and emissions needs to be adjusted. In our numerical procedure, the unit emissions are scaled down by a factor that increases at the rate $g_{Y}$. Such a reduction of unit emissions could happen using different technologies. For example, unit emission may be reduced by increased blending of non-polluting renewable biomass with the fossil fuels or preventing part of the emissions from reaching the atmosphere, e.g., via expanding implementation of carbon capture and storage (CCS) technology. Similar technology is discussed, for example, by Golosov et al. (2014). In addition, BGP requires a logarithmic utility function, i.e., $\chi=1$. The calibrated parameter values are summarized in Table $3{ }^{22}$

The model is inherently non-stationary, but we reformulate the model equations as a stationary set of difference equations for the specific balanced growth path. Then, we solve the model with perturbation methods using second-order Taylor approximation for the policy functions in the neighborhood of the steady-state of the reformulated stationary model (e.g. Schmitt-Grohé and Uribe 2004). The actual computation is performed using a DYNARE implementation of the method (Adjemian et al. 2011). The second-order approximation seems reasonable given the smoothness of the present model (Aruoba et al. 2006).

The use of perturbation method forces us to examine the model in the neighborhood of a balanced growth path. However, a general value function iteration of a non-stationary growth model with nine state variables (three carbon stocks, two temperature and capital stocks and population and autocorrelated productivity shock) is beyond the scope of this paper. A possibility would have been to apply current state linearization (Phillips and Evans 2017). However, their results suggest that with such a smooth model as ours, the off-steady-state-dynamics should not be that different from the one obtained from a steadystate linearization. Hence, we see that our impulse response function obtained from BGP analysis should be quite reasonable estimates also for off-BGP paths.

\subsection{Balanced Growth Path Properties}

The cost of abatement is determined by the elasticity of substitution (EOS) between the energy capital and the polluting input, $\gamma$. High EOS implies low abatement costs as non-polluting energy capital can be easily substituted for polluting input use. Analogously, low EOS describes an economy that is locked in using the polluting input. Table 4 reports the balanced growth path (BGP) values of key variables with three levels of EOS $(\gamma \in\{1,4,7\})$. These values are presented relative to the market solution which, due to model specification, does not depend on the elasticity of substitution. ${ }^{23}$ In the case of

Footnote 21 (continued)

model runs suggested that its effect on cyclical properties is significantly more modest. Thus, our impulse response results are relatively robust to the choice of the discount factor.

22 Details of calibration procedure are presented in Supplement S.3.

23 The BGP level of anthropogenic carbon stock is linearly dependent on emissions as well as on polluting input use. Thus, the percentage changes are the same for anthropogenic carbon stock, emissions and polluting input use. 
carbon price, the planning solution with Cobb-Douglas energy sector technology $(\gamma=1)$ acts as a reference level. Since the BGP growth rates of the variables are equal in the market solution and in all the planner solutions, the relative differences of the variables remain constant in the growth path.

With the given calibration, the unregulated market solution leads to a climate catastrophe in which temperature increases over eight degrees. ${ }^{24}$ The internalization of the climate externality by using carbon pricing improves the welfare and manages to reduce the atmospheric carbon stock as well as the resulting mean temperature. However, the climate change mitigation efforts and their effects depend on the elasticity of substitution, $\gamma$.

When energy capital and polluting input use are complements, the main avenue for mitigation is energy saving. Yet, the BGP production level is higher than in the market case as the climate damage reductions compensate for reductions in energy use. However, without proper abatement possibilities $(\gamma=1)$, the emissions pricing cannot prevent the climate catastrophe, as the temperature increase is still $83 \%$ of the unregulated baseline (Table 4). ${ }^{25}$ In the substitute case $(\gamma>1)$, the fossil fuel energy can be more easily replaced by the non-polluting energy technologies. Substantial investments to emission-free energy capital allow for efficient reduction of the fossil fuel use and still sustain a high level of energy use. With these technologies, the economy can maintain significantly higher production levels as climate change and resulting environmental damages are mitigated sufficiently. For example, with $\gamma=7$ the BGP temperature corresponds roughly to the $1.5^{\circ} \mathrm{C}$ temperature increase target (UNFCCC 2015).

Because of the slow decay of atmospheric carbon and the long relaxation times of temperature, a transient emission peak creates a slowly changing and long-lasting effects on both atmospheric carbon and global temperature, as indicated by the production loss response in Fig. 1a. ${ }^{26}$ We contrast this with a case where damages are modeled through atmospheric carbon stock, or equivalently, through temperature but assuming immediate reaction of temperature to the changes of carbon stock (e.g. Heutel 2012; Golosov et al. 2014; Annicchiarico and Di Dio 2015). We use the carbon cycle and damage model of Heutel (2012) as an example. ${ }^{27}$ Its production loss path differs notably from ours as the maximal effect follows instantly after the emission pulse. In addition, the effect dies out relatively fast. The time path of harmful effects from a transient emission determines also how the resulting marginal damage fluctuations are weighted when calculating the fluctuations of the SCC (Eq. (19)). Figure 1b shows these lag-weights, $w_{t s}$, in both formulations. It is clear that the choices of both the climate model and the damage variable can have an effect on the SCC fluctuations implied by the model.

\footnotetext{
24 The temperature change is extreme (e.g. Tokarska et al. 2016). The damage model is likely to be inadequate for temperature changes of this magnitude and is more suited for optimal policy analysis where temperature changes are smaller.

25 With lower annual discount rate, e.g. 1\%, the optimal carbon price becomes notably higher, and the climate change is more strongly mitigated also in the complement case.

26 Our dominant temperature relaxation time scale, 8.4 years, equals the estimate of IPCC (Boucher and Reddy 2008; Myhre et al. 2013) but is shorter than in recent economic models. For example, DICE2013R has two decay modes with time scales of 33 and 214 years, whereas, Gerlagh and Liski (2018b) use single mode with 50 year decay time scale. As a result, our GDP losses from a transient carbon emissions peak 30-40 years sooner than in the aforementioned papers (see e.g. Gerlagh and Liski 2018b).

27 Heutel uses a single carbon box with a half-life of 83 years and a quadratic production loss function $1-d\left(\tilde{S}_{t}\right)$, where $d=d_{2} \tilde{S}_{t}^{2}+d_{1} \tilde{S}_{t}+d_{0}$. The parameter values are $d_{2}=1.4647 \cdot 10^{-8}, d_{1}=-6.6722 \cdot 10^{-6}$ and $d_{0}=1.3950 \cdot 10^{-3}$ and $\tilde{S}_{t}=1000 / 3.67\left(S_{t}+S_{\text {pre }}\right)$ as Heutel uses unit $\mathrm{Gt}_{\mathrm{C}}$ and we have $\mathrm{Tt}_{\mathrm{CO}_{2}}$ and uses total atmospheric carbon instead of mere anthropogenic carbon.
} 
Table 3 Macroeconomic model parameters and their values

\begin{tabular}{lll}
\hline Symbol & Explanation & Value \\
\hline$\beta$ & Discount factor & 0.9963 \\
$\chi$ & Elasticity of intertemporal substitution (EIS) & 1 \\
$\nu$ & Frisch elasticity of labor supply & 2 \\
$\kappa$ & Scale of labor disutility & 0.98 \\
$\alpha_{L}$ & Labor (final good sector) share of national income & 0.57 \\
$\alpha_{K}$ & Capital (final good sector) share of national income & 0.32 \\
$\Delta_{y}$ & Temperature scale of production loss (K) & 19.35 \\
$\xi$ & Elasticity of marginal production loss & 1 \\
$L_{0}$ & Calibration labor share in final good sector & 0.89 \\
$K_{0}^{\text {fin }}$ & Calibration capital in final good sector & 7.80 \\
$\mu$ & Fossil fuel weight in energy sector CES & 0.66 \\
$\gamma$ & Elasticity of substitution (EOS) between $K^{\text {ene }}$ and $x$ & $1,4,7$ \\
$x_{0}$ & Calibration fossil fuel use (Gt/Qtr) & 8.64 \\
$K_{0}^{\text {ene }}$ & Calibration capital in energy sector & 0.867 \\
$B$ & Efficiency of labor in fossil fuel sector & 0.079 \\
$\delta_{\text {fin }}$ & Depreciation rate of capital in final good sector & 0.025 \\
$\delta_{\text {ene }}$ & Depreciation rate of capital in energy sector & 0.025 \\
$g_{A}$ & Annual growth rate of total factor productivity & 0.02 \\
$g_{N}$ & Annual growth rate of labor force & 0.01 \\
$\rho_{A}$ & Persistence of productivity shock $A$ & 0.95 \\
\hline
\end{tabular}

\begin{tabular}{llll}
\hline & \multicolumn{3}{l}{ Relative to Market solution (\%) } \\
\cline { 2 - 4 } & $\gamma=1$ & $\gamma=4$ & $\gamma=7$ \\
\hline Production & +8 & +39 & +53 \\
Consumption & +8 & +29 & +39 \\
Energy capital & +8 & +228 & +330 \\
Energy consumption & -21 & +5 & +29 \\
$\mathrm{CO}_{2}$ emissions & -33 & -79 & -94 \\
Temperature increase & -17 & -58 & -84 \\
& \multicolumn{2}{l}{ Relative to Planner solution } & $\gamma=1(\%)$ \\
Carbon price & - & +30 & -14 \\
\hline
\end{tabular}

Values are relative differences to no policy Market solution, except in the case of carbon price, where relative differences are to the Planner solution with $\gamma=1$. Relative differences remain constant, since growth rates are the same in the Market solution and all the Planner solutions 
(a)

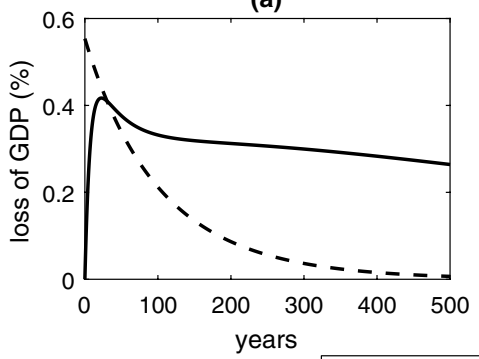

(b)

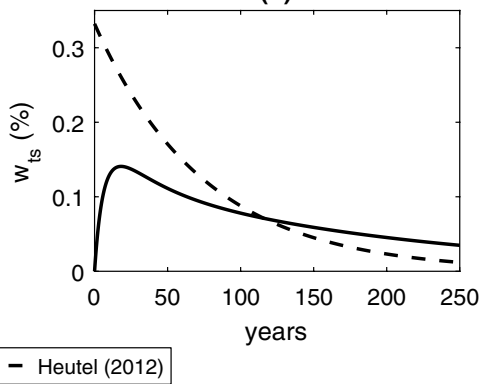

Fig. 1 The production losses following a transient $1 \mathrm{TtCO}_{2}$ emission (a) and the corresponding lag-weights $w_{t s}$ of future marginal climate damages (see Eq. (20)) (b), calculated for the balanced growth path with $\gamma=7$ using quarterly data. For comparison, the dashed lines represent a model, Heutel (2012), where damages are directly caused by the atmospheric carbon

\subsection{Economic Fluctuations and the Social Cost of Carbon}

We study the responses of the social cost of carbon and optimal $\mathrm{CO}_{2}$ emissions to economic fluctuations by perturbing the economy with a positive 1 percentage point total factor productivity (TFP) shock. Figures 2 and 3 show impulse responses to the shock in the planner's solution for the Cobb-Douglas energy sector technology, i.e., $\gamma=1$, and two cases of high substitutability between energy capital and polluting input, $\gamma=4$ and $\gamma=7$. Figure 2 represents the impulse responses for household decision variables, production inputs other than polluting input, and resulting production. Figure 3 shows the impulse responses for the social cost of carbon, $\mathrm{CO}_{2}$ emissions, i.e, polluting input use, and climate variables, i.e., atmospheric carbon stock and global temperature.

The elasticity of substitution between energy capital and polluting input, $\gamma$, does not have a notable impact on the cyclical properties of variables beyond the energy sector (Fig. 2). In addition, regardless of the value of the elasticity of substitution, the energy sector capital is increased. When the substitutability between energy sector capital and polluting input is low, the use of polluting input is increased as well (Fig. 3, Panel "Emission"). When the substitutability is high, the increasing energy sector capital replaces polluting input use and, thus, reduces its demand. Hence, with high substitutability the emissions increase initially but as the energy sector capital stock is built, polluting input use and, correspondingly, emissions decrease in the long run. Despite the initial positive response of emissions, a positive TFP shock decreases atmospheric pollution stock and temperature in the long run. In general, the impulse responses of pollution stock and temperature deviation follow logically the time-path of emissions: low elasticity of substitution, $\gamma$, leads to procyclical changes in pollution stock and temperature; high substitution case leads to countercyclical changes in these variables.

The slow pace of environmental process is implied through slow reaction, long duration, and the general weakness of the response of both the pollution stock and the temperature (Fig. 3). Especially the temperature deviation is long-lasting and lags behind the emission change with decades. ${ }^{28}$ The strength of the climate response depends on the elasticity of substitution. For the Cobb-Douglas case the relative climate deviations are three orders

28 The temperature deviation lasts for centuries (not shown here). 

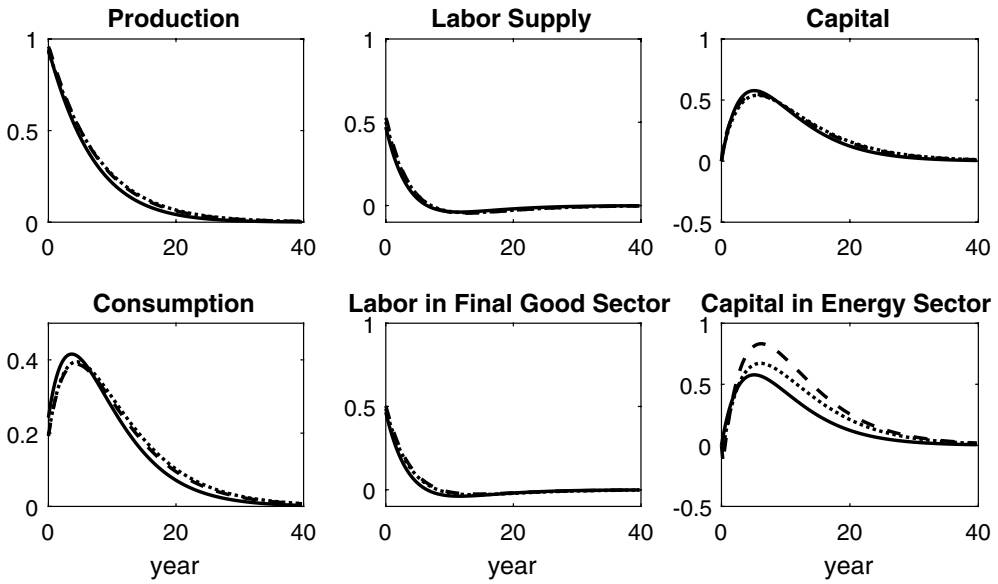

Fig. 2 Social planner: Impulse responses of macroeconomic variables to a 1 percentage positive productivity shock. The solid line represents the Cobb-Douglas production function $(\gamma=1)$, dashed line the substitute case with $\gamma=4$, and dotted line the strong substitute case with $\gamma=7$
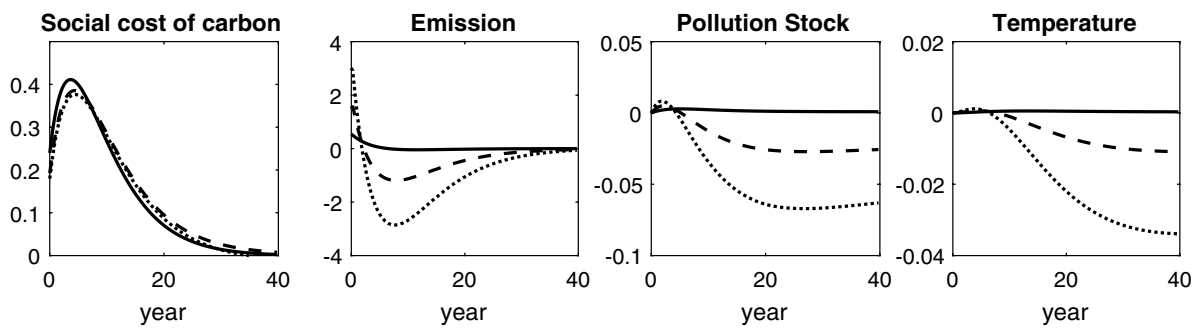

Fig. 3 Social planner: Impulse responses of environmental variables to a 1 percentage positive productivity shock. The solid line represents the Cobb-Douglas production function $(\gamma=1)$, dashed line the substitute case with $\gamma=4$, and dotted line the strong substitute case with $\gamma=7$

of magnitude smaller than the driving productivity shock. For other cases of elasticity of substitution, the climatic fluctuations are larger but still almost two orders of magnitude smaller than the driving shock. In absolute terms, the temperature impact is about one thousandth of ${ }^{\circ} \mathrm{C}$.

While the business cycle variations of $\mathrm{CO}_{2}$-emissions depend drastically on the elasticity of substitution, the impulse response of the SCC (Fig. 3) is strikingly similar in all three cases studied. These numerical results support the analytical findings that in the case of very slow environmental process, such as the climate change, the Pigouvian emission price closely follows the cyclical movements of the inverse of marginal utility of consumption. As a result, a persistent productivity shock causes equally persistent changes in the carbon price level. In the case of logarithmic utility $(\chi=1)$, the inverse marginal utility is equal to the consumption level. Thus, the resulting amplitude of carbon price movements is of the same magnitude as those of consumption.

The cyclical properties of macroeconomic variables can be summarized using correlations. Positive correlation with production level implies procyclicality and negative countercyclicality (see e.g. Kydland and Prescott 1982; Prescott 1986; Bilbiie et al. 2012). 
Table 5 presents the simulated correlations of the social cost of carbon, $\tau$, and emissions, $X$, with the production and consumption. The correlations are presented for the different values of the elasticity of substitution between energy capital and polluting input, $\gamma$. The correlations were calculated from simulated fluctuations around the balanced growth path using Monte Carlo random draws (Adjemian et al. 2011). The near unity correlation between consumption and the social cost of carbon, in all three cases, supports the analytical result that the relationship between the two variables is strikingly close (Sect. 4.2). The almost perfect correlation indicates that the changes in the SCC are mainly driven by the changes in current consumption level. Consequently, the other drivers, such as the cyclical changes of emissions and resulting changes in future climate damages, have only minor roles. The correlation between carbon price and the production level is also high. However, the near unity correlation with consumption suggests a rule-of-thumb policy recommendation that an adaptive $\mathrm{CO}_{2}$ tax should preferably be linked to the current consumption level.

Procyclical social cost of carbon does not necessarily imply countercyclical emissions. Instead, Table 5 (row $\operatorname{corr}(X, Y)$ ) suggests that the cyclicality of emissions is determined by the technology of the energy sector, i.e., the elasticity of substitution, $\gamma$. The correlations support the finding that the degree of substitution is a key determinant of the cyclical behavior of emissions. If energy capital and fossil fuel are complements, the emissions react procyclically but if they are substitutes the emissions turn countercyclical. If the substitutability between fossil fuel and energy capital is limited, the emissions are tied to the production level. In the case of Cobb-Douglas production technology $(\gamma=1)$, the correlation between production and emissions is high. ${ }^{29}$ This would suggest an adaptive cap and trade policy, where the emission cap is tied to the production level. However, this approach applies only to the case where substitution possibilities of polluting input are very limited. If the economy reduces $\mathrm{CO}_{2}$ emissions by using non-polluting energy technologies that are substitutes of fossil fuels, such as photovoltaics and wind power, the close correlation of the polluting input and production is likely to brake down ( $\gamma=4$ and $\gamma=7$ in Table 5). Since the correlation between emissions and production level is heavily technology dependent, it seems that an adaptive cap and trade policies would be more difficult to design than an adaptive tax policy, which can be indexed to consumption regardless of technology.

Table 5 shows that with a low substitutability of energy capital and polluting input, the correlation between the SCC and consumption is nearly perfect. However, if the substitutability is high, the correlation deviates from unity. In that case the factors other than the current marginal utility have a non-negligible effect on optimal price variation. To illustrate the drivers of the SCC fluctuation, Fig. 4 shows the decomposition of the SCC response in the

Table 5 Cross-correlations of the social cost of carbon, $\tau$, the emissions, $X$, production, $Y$, and consumption, $C$

\begin{tabular}{lccc}
\hline & $\gamma=1$ & $\gamma=4$ & $\gamma=7$ \\
\hline $\operatorname{corr}(\tau, C)$ & 1.00 & 1.00 & 0.96 \\
$\operatorname{corr}(\tau, Y)$ & 0.90 & 0.88 & 0.86 \\
$\operatorname{corr}(X, Y)$ & 0.77 & -0.31 & -0.43 \\
$\operatorname{corr}(X, \tau)$ & 0.42 & -0.72 & -0.77 \\
\hline
\end{tabular}

Correlations are obtained from stochastic model simulations around the balanced growth path

\footnotetext{
29 The correlation 0.77 with $\gamma=1$ corresponds roughly to the current technological conditions as implied by the calibration by Heutel (2012). With a lower elasticity of substitution, the correlation is even higher (not shown).
} 
(a)

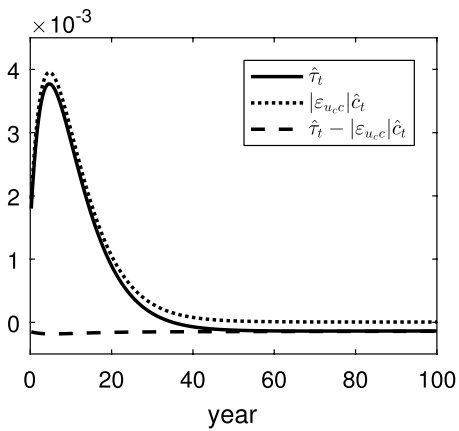

(b)

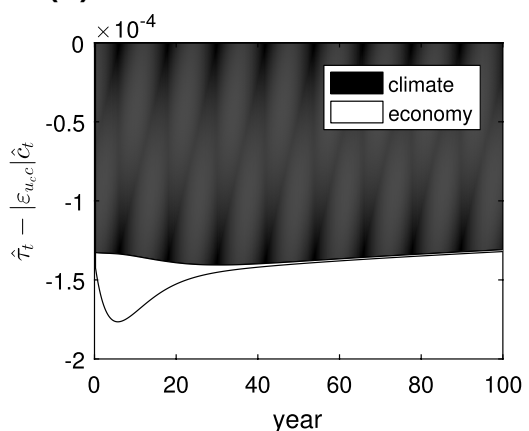

Fig. 4 Decomposition of the response of the social cost of carbon. Panel a presents the response of the SCC (solid line), the marginal utility (dotted line) and their difference (dashed line). This difference is a superposition of climate and economic effects $(\mathbf{b})$. See details in text

high substitutability case $(\gamma=7)$ using the decomposition in Eq. (21). Panel (a) shows that the optimal carbon price response is still mostly driven by the current marginal utility. Yet, there is a relatively constant residual contribution that does not vanish even in the long run when the marginal utility fluctuation has already petered out. Panel (b) shows the decomposition of this residual factor. The main contribution is due to the changes in the future climate conditions ("climate"). The contribution represents the terms presented in the "Env." column of Table 1 (i.e., $\sum_{s} w_{t s}\left(\hat{\omega}_{t s}+\varepsilon_{\Psi D} \hat{D}_{t+s}\right)$ ). The impact of future economic fluctuations ("economy") on the SCC is relatively modest and short-lived compared to the climate effects. The effects of these economic fluctuations are represented by terms $\sum_{s} w_{t s}\left(\hat{Y}_{t+s}-\left|\varepsilon_{u_{c} c}\right| \hat{c}_{t+s}\right)$ in the "Econ." column of Table 1. Both of these climate and economic factors tend to reduce the SCC fluctuation, which corresponds to the Case 4 in Table 1.

\subsection{Optimal Versus Fixed Policies}

Correlations between optimal carbon price and emissions in Table 5 suggest that carbon price fluctuation may have a weak effect on the equilibrium emission fluctuations. To test the economic effects of the optimal carbon price fluctuations we compare the optimal outcomes with the ones resulting from an optimally set, yet, fixed emission tax and emission cap. Figure 5 compares the optimally set fixed emission tax and emission cap to the optimally adjusted carbon price through their effects on the productivity shock responses of five key variables. The rows present the responses with two different energy sector technologies in which the polluting input and the energy capital are either Cobb-Douglas $(\gamma=1)$ or strong $(\gamma=7)$ substitutes, respectively.

The responses of output and consumption are not notably affected by the elasticity of substitution, $\gamma$, or the policy scheme (see Fig. 5 for the responses of consumption). With the Cobb-Douglas technology $(\gamma=1)$, the policy scheme does not affect the responses of the energy capital or the temperature either (top row of Fig. 5), despite the relatively strong increase of carbon price in the case of emission trading policy with a fixed emissions cap. The similarity of macroeconomic fluctuations is likely to be a consequence of the general lack of abatement possibilities in the economy if the EOS, $\gamma$, is unity.

The case of strong substitutability between energy capital and polluting input $(\gamma=7)$ creates more variation in the responses (bottom row of Fig. 5). In general, with the strong 

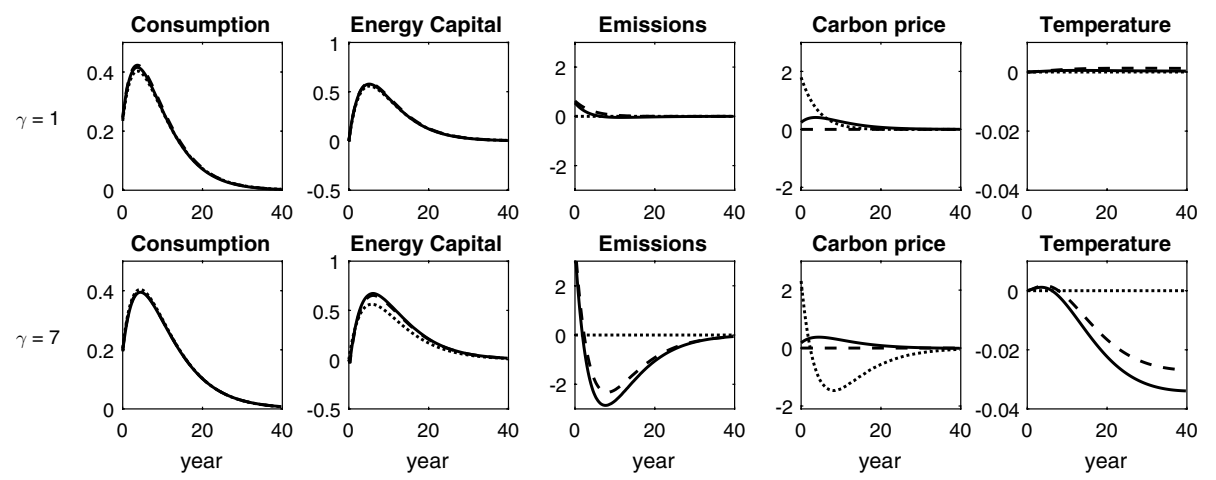

Fig. 5 Comparison of fixed policies with the optimally adjusting carbon price. Responses to one percentage positive productivity shock for optimally adjusting policy (solid line), fixed carbon tax (dashed line), and fixed emission quantity policy (dotted line). The first row presents the case where energy sector technology is Cobb-Douglas $(\gamma=1)$ and the second row presents the case where energy sector capital and polluting input are strong substitutes $(\gamma=7)$

substitutability, an economy with a fixed emission tax has similar reactions to a productivity shock compared to an economy with the optimally adjusted carbon price. The similarity of emission responses suggests that the effect of a procyclical carbon price has only a minor role in the countercyclicality of the emissions. Instead, if the emission cap is fixed, there is a strong and long-lasting countercyclical carbon price response that can have macro implications as indicated by the slightly altered response of the energy capital investments. With fixed emission cap, the countercyclicality of carbon price follows directly from the stronger positive impact of a positive TFP shock on the marginal production of energy capital than on the marginal production of fossil input. Thus, reduced demand for polluting input use slackens the fixed emission cap regulation and reduces emission price.

In financial crises, such as 2008 Great Recession, economies typically face strong and long-lasting shocks (Cerra and Saxena 2008). Figure 6 shows a case of persistent shock, where the one percent positive TFP shock has persistence $\rho_{A}=0.999$. Under such persistent shocks the negative effects of non-optimal policies are amplified (Fig. 6). While in a case of high substitutability between energy capital and polluting input $(\gamma=7)$ the persistent shock leads to greater changes in environmental quality, the SCC remains procyclical. Fixed emission policies may lead to large deviations of emissions prices from the optimal level. However, these price deviations should be extreme to cause notable changes in macroeconomic variables.

The carbon price panels of Fig. 6 highlight the fact that with low substitutability $(\gamma=1)$, the fixed cap seems to better mimic the SCC trajectory than the fixed prices. In the case of high substitutability $(\gamma=7)$, the situation is reversed. The result can be analyzed through the static prices versus quantities framework, where in the basic setup the relative slopes of marginal environmental benefits and marginal abatement costs dictate the relative efficiency of the two policies (Weitzman 1974). Since the climate system implies flat marginal benefits, a fixed tax is in general preferred over a fixed cap regulation (Hoel and Karp 2001, 2002; Newell and Pizer 2003). However, the relative performance of fixed cap and fixed tax regulations is affected by the correlation between fluctuations of marginal benefit and marginal cost functions (Stavins 1996). 

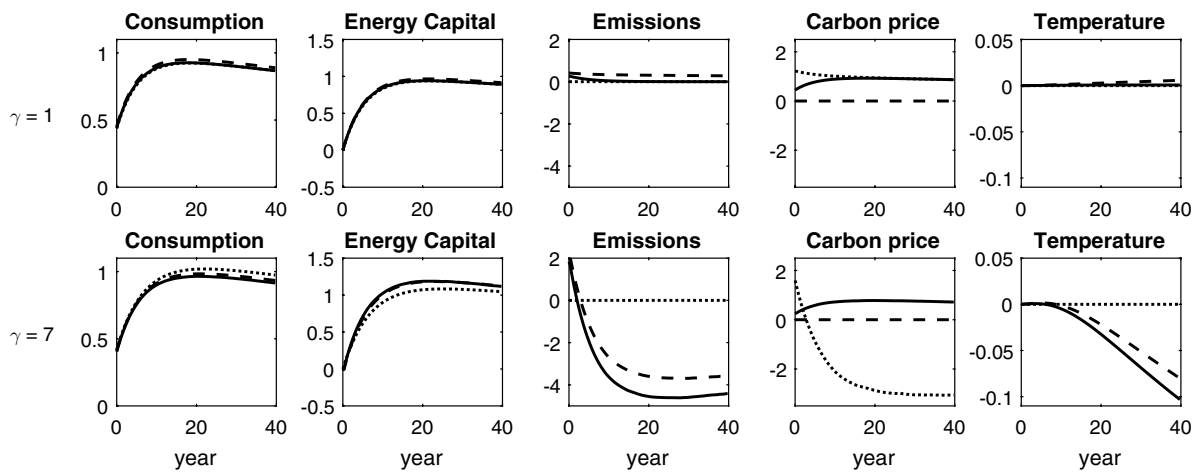

Optimal - - Fixed tax …..... Fixed emissions

Fig. 6 Comparison of fixed policies with the optimally adjusting carbon price, when the technology shock is persistent, $\rho_{A}=0.999$. Responses to one percentage positive productivity shock for optimally adjusting policy (solid line), fixed carbon tax (dashed line), and fixed emission quantity policy (dotted line). The first row presents the case where energy technology is Cobb-Douglas $(\gamma=1)$ and the second row presents the case where energy sector capital and polluting input are strong substitutes $(\gamma=7)$

The marginal environmental benefits are always procyclical in our model. However, the cyclicality of marginal abatement costs depends on the energy technology. If there are only few substitution possibilities for fossil fuels $(\gamma=1)$, the marginal costs are procyclical. Instead, if the substitution is easy, the marginal costs are countercyclical. This is shown by the procyclical SCC together with procyclical and (strongly) countercyclical optimal emissions, respectively. Thus, the correlation between marginal benefits and costs is positive with the low substitution case and negative with the high substitution case. Stavins (1996) shows that positive correlation favors quantity instruments whereas negative correlation favors price instruments. This finding seems to apply also in the dynamic case presented here: with low substitution case the positive correlation improves the performance of a fixed cap regulation. In a high substitutability case, the negative correlation further improves the relative performance of a tax regulation. ${ }^{30}$

\section{Discussion}

\subsection{Cyclical Properties of Optimal Emission Prices}

We found that the marginal social cost of an externality, i.e., the Pigouvian emission price, is likely to be procyclical, especially, if the environmental processes involved are slow and long-lasting. If the processes are fast, there is an increased possibility for the business cycle variation in environmental harm turning the emission price countercyclical. Yet, these variations in environmental effects need to be strong enough to counter the procyclical forces of increased production level. All in all, the procyclicality of the Pigouvian emission price seems to be a rather robust result. For example, it does not rely on any specific economic

\footnotetext{
${ }^{30}$ If the economy faces a strong shock that increases the productivity of clean technology, abatement costs and possibly also the SCC decline. In this kind of strong positive correlation case, a fixed cap can also outperform a fixed price instrument (Karp and Traeger 2017).
} 
shock driving the economic fluctuations. What is required is a positive correlation between the production level and the final good consumption. This result is also widely applicable, as our modeling framework for environmental damages is very general.

Our quantitative assessment showed that the SCC fluctuations are driven mainly by the marginal utility of consumption. With the constant elasticity of intertemporal substitution the carbon price follows the consumption level in almost perfect correlation. This result is independent of assumed production technology of the energy sector. Since climate is a prime example of a slow environmental process, the quantitative assessment supported the implications of the analytical examination.

Interestingly, previous papers producing simple formulas for the SCC (e.g. Golosov et al. 2014) have implied that the SCC is proportional to current aggregate production level. In fact, this is also the case with our model, when the economy follows a balanced growth path (see Eq. (18)). Yet, due to above described reasons, the short-term SCC fluctuations around this growth path are more strongly linked to changes in consumption than in output. The SCC fluctuations are directly linked to the output fluctuations only if the household savings rate remains constant. Empirically this is not the case as the comovement of output and consumptions are not perfectly correlated (e.g. Kydland and Prescott 1990).

Our results suggest that in the climate change case the optimally set fixed price or quantity regulation can yield reasonably good outcomes compared to the optimally fluctuating carbon pricing. However, Lintunen and Kuusela (2018) have recently demonstrated that a cap and trade policy that is allowed to deviate from the optimal BGP price path can yield substantial welfare losses. Thus it seems that it is better to maintain a rigid regulation close to the BGP price levels than allow too much price fluctuations.

Previous studies focusing on business cycles and carbon regulation (Heutel 2012; Annicchiarico and Di Dio 2015) have also found that the optimal carbon tax should respond positively to a TFP shock. They modeled the carbon emissions as a function of GDP (see also Nordhaus and Sztorc 2013). In addition, they modeled climate damages through atmospheric carbon stock and not the global temperature. This alters the time structure of emission-damage linkage by speeding up the harmful effects of emissions and, therefore, increasing the role of components other than current consumption on the optimal carbon price fluctuations. Together with a direct link between the GDP and damages, this may exacerbate the influence of the GDP on the optimal carbon price.

\subsection{Cyclical Properties of Optimal $\mathrm{CO}_{2}$ Emissions}

The analysis of the cyclicality of the emissions is not straightforward, and needs to be done with quantitative methods. Thus, our results cover only the cyclicality of $\mathrm{CO}_{2}$ emissions. Our main finding was that whereas the SCC develops similarly irrespective of the energy production technology, the emission fluctuations are dictated by the technology. If the polluting input and the non-polluting energy capital are complements, the emissions tend to be procyclical, whereas increased substitutability lead to countercyclical emissions. This observation is novel as the previous business cycle literature, which has been calibrated to current conditions, have provided evidence only for procyclical emissions (Heutel 2012; Angelopoulos et al. 2013; Annicchiarico and Di Dio 2015; Grodecka and Kuralbayeva 2015). The comparison with a fixed tax showed that the changes in the SCC have limited influence on resulting emissions and the main driver here is the technology, i.e., the elasticity of substitution between energy capital and polluting input. 
The calibration by Heutel (2012) shows that carbon emissions in US are currently procyclical. We demonstrated that the procyclicality of emissions is connected to the low substitutability between fossil fuels and energy sector capital. However, our results also imply that in future a possible technological change towards higher substitutability might lead to countercyclical emissions. According to IEA (2016) the competitiveness and use of cleaner energy sources, such as wind and photovoltaics, has already increased greatly. Our calculations on the growth path temperature under different technologies demonstrated that the higher substitutability is indeed necessary to avoid significant climate warming. Public policies such as subsidies to clean technology could promote the change. However, the technological change and the role of policies in it are outside the scope of this paper but are analysed for example in Acemoglu et al. (2016).

\subsection{Caveats and Potential Extensions}

The analytical reasoning we provide is rather general and, therefore, its implications are robust. Our quantitative assessment focuses on the effects of differing timescales of economic and climatic processes, and the role of energy sector technology. In the analysis we utilize a basic RBC model and examine macroeconomic TFP shocks. Naturally, the model framework could be extended to, e.g., New Keynesian premises and analysis could have been done with real and nominal rigidities and additional macroeconomic shocks. Although, these extensions can provide additional insight on the details of macroeconomic responses, they do not change the effects of timescale disparity nor the strong consumption linkage of the SCC. We examined economic fluctuations using perturbations around a balanced growth path. Examining business cycle fluctuations from an arbitrary initial state with value function iteration (Cai and Lontzek 2019) could yield additional details to policy recommendations particularly if economy is affected by significant non-linearities such as tipping points. Finally, the quantitative assessment relies on a CES production function, which does not allow for zero emissions. Therefore, we modified the climate model to support a positive emission BGP. However, the adaptation manages to satisfy the key features of the climate system: long lags and very long relaxation timescales. All in all, there are several ways one could extend the quantitative assessment to provide more rich description of the economy. We leave these to future endeavors.

\section{Conclusions}

We developed a real business cycle model to analyze the business cycle properties of both the Pigouvian emission price and the optimal emissions. Our results suggest that, in general, the emission prices should be adjusted procyclically. This is the case especially if emissions propagate to environmental harm slowly. In this case, the emission price fluctuation is mostly driven by the changes in the marginal utility of consumption. However, optimal emission prices can be countercyclical under exceptional circumstances.

Unlike the price variation, the optimal business cycle variation of emissions depends significantly on the production technology in the polluting sectors. In addition, our quantitative assessment in the case of $\mathrm{CO}_{2}$ implies that emission fluctuations may have relatively complicated time structure. These observations suggest that over the business cycle it is more straightforward to optimally adjust an emission tax system than a cap and trade system. 
Since the optimal reactions of carbon price follow closely the marginal utility of consumption they are quite limited in magnitude. During the Great recession the price of $\mathrm{CO}_{2}$ emission in the European emission trading scheme plunged and it has recovered only recently. As the social cost of carbon is reasonably stable over the business cycles, also the price fluctuations in quantity based climate policies should be quite limited. Therefore, our results suggest that observed changes in the carbon prices are probably excessive. In addition, we find that under the business cycle fluctuations of normal magnitude a tax, which has been fixed to its optimal growth path levels, is almost as efficient policy tool as the cyclically varying tax rate. The cyclical phases have limited effects on global temperature itself as the warming is driven by the long-term trend of using fossil fuels.

\section{Appendix 1}

\section{Environmental Lag-Structure}

\section{The General Formulation}

A dynamic system leading from emissions to environmental consequences can be complicated, especially, when one examines stock pollutants. Namely, the dynamics of the pollution stock can be complicated and the environmental processes can react to pollution stock with different lag-structures and the relation can be non-linear. Here, we represent a general formulation of a dynamic system that consists of sets of difference equations. Such structure have been used, e.g., for $\mathrm{CO}_{2}$ stocks in atmosphere and oceans (pollution stocks) and global temperature change (environmental impact) (e.g. Nordhaus 2008). Naturally, such a general formulation can be used for describing other stock pollutants and their environmental impacts.

The pollutant stock is represented by m-box model, i.e., it is described by a $(m \times 1)$ vector $S_{t}$. Depending on the application, the elements of the vector, i.e., "boxes", may or may not have a physical interpretation. The pollutant level is driven by scalar $X_{t}$, which represents emissions. The linear equation of motion is

$$
S_{t}=\mathbf{\Sigma} S_{t-1}+\mathbf{E} X_{t},
$$

where $\boldsymbol{\Sigma}$ is a $(m \times m)$ matrix that captures the decay of stock components and, if not diagonal, also the flows between stock components. The $(m \times 1)$ vector of parameters $\mathbf{E}$ describes the allocation of emissions into stock components, that is, $\mathbf{1}_{m}^{\prime} \mathbf{E} \leq 1$, where $\mathbf{1}_{m}$ is a $(m \times 1)$ vector of ones.

Similarly we specify a n-box model for the environmental processes. The values of the boxes are collected in a $(n \times 1)$ vector $D_{t}$ with equation of motion

$$
D_{t+1}=\Delta D_{t}+\Lambda \Phi\left(S_{t}\right)
$$

Here $\boldsymbol{\Delta}$ is a $(n \times n)$ matrix that captures the decay of state variables and, if not diagonal, also the flows between states. Scalar function $\Phi$ gives the, possibly, non-linear forcing caused by the pollution stock $S_{t}$ and $(n \times 1)$ parameter vector $\boldsymbol{\Lambda}$ translates the forcing to components of $D_{t+1}$.

Using recursion, we can formulate the effect of past emissions on pollution stocks

$$
S_{t+j-i}=\boldsymbol{\Sigma}^{j-i+1} S_{t-1}+\sum_{k=0}^{j-i} \boldsymbol{\Sigma}^{k} \mathbf{E} X_{t+j-i-k}
$$


and the effect of past pollution stocks on environmental harm causing state

$$
D_{t+j+1}=\Delta^{j+1} D_{t}+\sum_{i=0}^{j} \Delta^{i} \Lambda \Phi\left(S_{t+j-i}\right) .
$$

Together, Eqs. (32) and (33) lead to equation

$$
D_{t+j+1}=\boldsymbol{\Delta}^{j+1} D_{t}+\sum_{i=0}^{j} \boldsymbol{\Delta}^{i} \Lambda \Phi\left(\boldsymbol{\Sigma}^{j-i+1} S_{t-1}+\sum_{k=0}^{j-i} \boldsymbol{\Sigma}^{k} \mathbf{E} X_{t+j-i-k}\right) .
$$

Given that $D_{0}=0$ and $S_{-1}=0$, we can state ${ }^{31}$

$$
D_{t}=\sum_{i=1}^{t} \Delta^{i-1} \Lambda \Phi\left(S_{t-i}\right)
$$

where

$$
S_{t-i}=\sum_{j=0}^{t-i} \boldsymbol{\Sigma}^{t-i-j} \mathbf{E} X_{j}
$$

The emission $X_{t}$ impacts on the state of environment on period $t+k(k \geq 1)$ through two channels. First, it causes a long lasting pollution stock change that induces forcing. Second, the change in the state of environment is persistent due to the inertia in the environmental system. The effect is directly obtained through partial differentiation:

$$
\frac{\partial D_{t+k}}{\partial X_{t}}=\sum_{i=1}^{k} \boldsymbol{\Delta}^{i-1} \boldsymbol{\Lambda} \frac{\partial \Phi\left(S_{t+k-i}\right)}{\partial S_{t+k-i}} \boldsymbol{\Sigma}^{k-i} \mathbf{E}=: \boldsymbol{\Omega}_{t k}
$$

where $\partial \Phi / \partial S$ is a $(1 \times m)$ gradient vector of the forcing function. $\boldsymbol{\Omega}_{t k}$ is a $(n \times 1)$ vector summarizing the marginal effect of emission increment at $t$ on the environmental harm state $k$ periods later.

With slight abuse of notation we present the state of environment through a scalar function $D_{t}\left(\chi_{t}\right)$, which is driven by the history of emissions $\chi_{t}:=\left(X_{t-1}, X_{t-2}, \ldots, X_{0}\right)$. Given that the social harm is caused by the sum of components of vector $D_{t}$, the lag structure, $\omega_{t k}$, of our analytical model is given by

$$
\omega_{t k}=\frac{\partial D_{t+k}\left(\chi_{t+k}\right)}{\partial X_{t}}=\mathbf{1}_{n}^{\prime} \mathbf{\Omega}_{t k}
$$

\section{The Climate Model}

The climate model presented in Sect. 5.1 is of the form introduced by Eqs. (30) and (31). Using the notation of these equations we have

\footnotetext{
31 The assumptions imply that emissions before period zero are either zero, or are such that they cancel each others in effect.
} 


$$
\boldsymbol{\Sigma}=\left[\begin{array}{lll}
1-\sigma_{1} & 0 & 0 \\
0 & 1-\sigma_{2} & 0 \\
0 & 0 & 1-\sigma_{3}
\end{array}\right] \quad \text { and } \quad \mathbf{E}=\left[\begin{array}{c}
\varepsilon_{1} \\
\varepsilon_{2} \\
\varepsilon_{3}
\end{array}\right]
$$

and

$$
\boldsymbol{\Delta}=\left[\begin{array}{ll}
1-\eta_{1} & 0 \\
0 & 1-\eta_{2}
\end{array}\right] \quad \boldsymbol{\Lambda}=\left[\begin{array}{l}
\eta_{1} \pi_{1} \\
\eta_{2} \pi_{2}
\end{array}\right] \quad \text { and } \quad \Phi\left(S_{t}\right)=\frac{\log \left(1+S_{t} / S_{\text {pre }}\right)}{\log 2}
$$

where $S_{t}=\sum_{i=1}^{3} S_{i t}$. Since in the model the climate damages are determined by the sum of the temperature sub-components, i.e. $D_{t}=\sum_{j=1}^{2} D_{j t}$, we obtain the lag structure $\omega_{t s}$ from (38). Using the above definitions (39), (40), and (37) in Eq. (38) we directly end up with

$$
\omega_{t s}=\sum_{u=0}^{s-1} \Phi^{\prime}\left(S_{t+u}\right) \sum_{i=1}^{3} \varepsilon_{i}\left(1-\sigma_{i}\right)^{u} \sum_{j=1}^{2} \eta_{j} \pi_{j}\left(1-\eta_{j}\right)^{s-u-1} .
$$

Similar formulation has been utilized, for example, by Gerlagh and Liski (2018b) and van den Bijgaart et al. (2016).

\section{Appendix 2}

\section{Fast Environmental Process}

Environmental process is fast when both the damage process is fast and the pollutant stock short-lived. Given the structure of our model, in extreme case, the current emissions determine the next period level of the environmental harm. Unlike in the case of slow environmental process (Sect. 4.2), when the environmental process is fast, the weights $w_{t 1} \equiv 1$, for all $t$ and they have no role in the fluctuation analysis. Instead, Eq. (21) can be written as

$$
\hat{\tau}_{t}=\left|\varepsilon_{u_{c} c}\right| \hat{c}_{t}+\mathbb{E}_{t}\left[\hat{Y}_{t+1}-\left|\varepsilon_{u_{c} c}\right| \hat{c}_{t+1}+\hat{\omega}_{t 1}+\varepsilon_{\Psi D} \hat{D}_{t+1}\right] .
$$

When the environmental harm emerges only as a production loss (42), the consumption smoothing causes the difference of terms $\left|\varepsilon_{u_{c} c}\right| \hat{c}_{t}-\mathbb{E}_{t}\left|\varepsilon_{u_{c} c}\right| \hat{c}_{t+1}$ to be of negligible order of magnitude compared to the fluctuation in production, $\hat{Y}_{t+1}$. Since the production term always dominates over the marginal consumption terms, we drop the consumption terms from the following analysis. The remaining terms in Eq. (42) and their cyclicalities are collected in Table 6 . The term $\hat{Y}_{t+1}$ is naturally procyclical. The cyclicalities of climate terms are case-dependent.

The second column of Table 6 depicts the terms that are related to the emissions-toharm process, $\hat{\omega}_{t 1}$, and to the environmental harm, $\hat{D}_{t+1}$. The driver here is the correlation of emission level, $\hat{X}_{t}$, with the production level $\hat{Y}_{t}$. The propagation process, $\hat{\omega}_{t}$, reacts to the development in emission level. The reaction can be either way, depending on the process in question and is case dependent. The environmental damage term, $\varepsilon_{\Psi_{D}} \hat{D}_{t+1}$, is more straightforward. By assumption, the elasticity $\varepsilon_{\Psi D}$ is positive. Since the increased emissions increase environmental harm, response $\hat{D}_{t+1}$ follows the response of emissions.

As mentioned in the case of the slow environmental process, if the economy is close to an environmental tipping point the damage elasticity $\varepsilon_{\Psi D}$ could be very large. As a result, 
Table 6 Fluctuation summary for a fast process

\begin{tabular}{llll}
\hline & MU & Env. & Price \\
& $\hat{Y}_{t+1}$ & $\hat{\omega}_{t 1}+\varepsilon_{\Psi D} \hat{D}_{t+1}$ & $\hat{\tau}_{t}$ \\
\hline Case 5 & + & + & + \\
Case 6 & + & - & $?$ \\
\hline
\end{tabular}

See details in text. '十' sign indicates procyclicality and '-' sign countercyclicality of the corresponding term

the environmental harm term, $\varepsilon_{\Psi D} \hat{D}_{t+1}$, may well be the largest ones in the Eq. (42) and, therefore, it can determine the cyclical properties of the optimal emission price. However, it is not clear whether such tipping points are compatible with a fast environmental process setup.

To summarize the discussion about rapidly transmitted emissions, the optimal emission price is likely to be procyclical, especially, when the emissions are procyclical (case 5). But, in the case of countercyclical emissions with damage elasticity $\varepsilon_{\Psi D}$ large enough (case 6), a countercyclical optimal emission price is possible.

Supplementary Information The online version contains supplementary material available at https://doi. org/10.1007/s10640-021-00581-x.

Acknowledgements Jussi Lintunen gratefully acknowledges the funding from the Academy of Finland grant no. 295870. The authors also wish to thank Matti Liski for constructive discussions and Bjart Holtsmark, Marlène Isoré, Martin Quaas, and anonymous referees, and participants at the 35th Annual Meeting of the Finnish Economic Association, First Nordic Annual Environmental and Resource Economics and 23rd Annual Conference of European Association of Environmental and Resource Economists for providing useful comments.

Funding Open access funding provided by Natural Resources Institute Finland (LUKE).

Open Access This article is licensed under a Creative Commons Attribution 4.0 International License, which permits use, sharing, adaptation, distribution and reproduction in any medium or format, as long as you give appropriate credit to the original author(s) and the source, provide a link to the Creative Commons licence, and indicate if changes were made. The images or other third party material in this article are included in the article's Creative Commons licence, unless indicated otherwise in a credit line to the material. If material is not included in the article's Creative Commons licence and your intended use is not permitted by statutory regulation or exceeds the permitted use, you will need to obtain permission directly from the copyright holder. To view a copy of this licence, visit http://creativecommons.org/licenses/by/4.0/.

\section{References}

Acemoglu D, Aghion P, Bursztyn L, Hemous D (2012) The environment and directed technical change. Am Econ Rev 102(1):131-166

Acemoglu D, Akcigit U, Hanley D, Kerr W (2016) Transition to clean technology. J Polit Econ 124(1):52-104

Adjemian S, Bastani H, Juillard M, Karamé F, Maih J, Mihoubi F, Perendia G, Pfeifer J, Ratto M, Villemot S (2011) Dynare: reference manual version 4. Dynare working papers 1, CEPREMAP

Angelopoulos K, Economides G, Philippopoulos A (2013) First-and second-best allocations under economic and environmental uncertainty. Int Tax Public Finance 20(3):360-380 
Annicchiarico B, Di Dio F (2015) Environmental policy and macroeconomic dynamics in a new Keynesian model. J Environ Econ Manag 69:1-21

Anthoff D, Tol RS (2013) The uncertainty about the social cost of carbon: a decomposition analysis using fund. Clim Change 117(3):515-530

Archer D (2005) Fate of fossil fuel $\mathrm{CO}_{2}$ in geologic time. J Geophys Res Oceans 110(C9):1-6

Aruoba SB, Fernandez-Villaverde J, Rubio-Ramirez JF (2006) Comparing solution methods for dynamic equilibrium economies. J Econ Dyn Control 30(12):2477-2508

Barrage L (2020) Optimal dynamic carbon taxes in a climate-economy model with distortionary fiscal policy. The Review of Economic Studies 87(1):1-39

Bilbiie FO, Ghironi F, Melitz MJ (2012) Endogenous entry, product variety, and business cycles. J Polit Econ 120(2):304-345

Boucher O, Reddy M (2008) Climate trade-off between black carbon and carbon dioxide emissions. Energy Policy 36(1):193-200

Cai Y, Lontzek TS (2019) The social cost of carbon with economic and climate risks. J Polit Econ 127(6):2684-2734

Cerra V, Saxena SC (2008) Growth dynamics: the myth of economic recovery. Am Econ Rev 98(1):439-57

Climate Watch (2020) Historical GHG emissions. https://www.climatewatchdata.org/ghg-emissions?break $\mathrm{By}=$ sector

Dietz S, Stern N (2015) Endogenous growth, convexity of damage and climate risk: how Nordhaus' framework supports deep cuts in carbon emissions. Econ J 125(583):574-620

Dissou Y, Karnizova L (2016) Emissions cap or emissions tax? A multi-sector business cycle analysis. J Environ Econ Manag 79:169-188

Doda B (2016) How to price carbon in good times... and bad! Wiley Interdiscip Rev Clim Change 7(1):135-144

Gerlagh R, Liski M (2018a) Carbon prices for the next hundred years. Econ J 128(609):728-757

Gerlagh R, Liski M (2018b) Consistent climate policies. J Eur Econ Assoc 16(1):1-44

Golosov M, Hassler J, Krusell P, Tsyvinski A (2014) Optimal taxes on fossil fuel in general equilibrium. Econometrica 82(1):41-88

Greenstone M, Kopits E, Wolverton A (2013) Developing a social cost of carbon for us regulatory analysis: a methodology and interpretation. Rev Environ Econ Policy 7(1):23-46

Grodecka A, Kuralbayeva K (2015) The price vs quantity debate: climate policy and the role of business cycles. Working paper 177, Grantham Research Institute on Climate Change and the Environment

Heutel G (2012) How should environmental policy respond to business cycles? Optimal policy under persistent productivity shocks. Rev Econ Dyn 15(2):244-264

Hodrick RJ, Prescott EC (1997) Postwar US business cycles: an empirical investigation. J Money Credit Bank 26(1):1-16

Hoel M, Karp L (2001) Taxes and quotas for a stock pollutant with multiplicative uncertainty. J Public Econ 82(1):91-114

Hoel M, Karp L (2002) Taxes versus quotas for a stock pollutant. Resour Energy Econ 24(4):367-384

Hope $\mathrm{C}$ (2011) The social cost of $\mathrm{CO}_{2}$ from the PAGE09 model. Economics E-journal Discussion Paper No. 2011-39. http://www.economics-ejournal.org/dataset/PDFs/discussionpapers_2011-39.pdf

IEA (2016) World energy outlook 2016. OECD/IEA, Paris

IPCC (2013) Summary for policymakers. In: Stocker T, Qin D, Plattner G, Tignor M, Allen S, Boschung J, Nauels A, Xia Y, Bex V, Midgley P (eds) Climate change 2013: the physical science basis. Contribution of working group I to the fifth assessment report of the intergovernmental panel on climate change. Cambridge University Press, Cambridge, pp 3-29

Joos F, Roth R, Fuglestvedt JS, Peters GP, Enting IG, Wv Bloh, Brovkin V, Burke EJ, Eby M, Edwards NR et al (2013) Carbon dioxide and climate impulse response functions for the computation of greenhouse gas metrics: a multi-model analysis. Atmos Chem Phys 13(5):2793-2825

Karp L, Traeger C (2017) Smart cap, presentation at 23rd annual conference of the European Association of Environmental and Resource Economists

Kydland FE, Prescott EC (1982) Time to build and aggregate fluctuations. Econometrica 50(6):1345-1370

Kydland FE, Prescott EC (1990) Business cycles: real facts and a monetary myth. Fed Reserve Bank Minneap Q Rev 14(2):3-18

Lemoine D, Traeger C (2014) Watch your step: optimal policy in a tipping climate. Am Econ J Econ Policy 6(1):137-166

Lintunen J, Kuusela O-P (2018) Business cycles and emission trading with banking. Eur Econ Rev 101:397-417

Lontzek TS, Cai Y, Judd KL, Lenton TM (2015) Stochastic integrated assessment of climate tipping points indicates the need for strict climate policy. Nat Clim Change 5(5):441-444 
Myhre G, Shindell D, Bréon F-M, Collins W, Fuglestvedt J, Huang J, Koch D, Lamarque J-F, Lee D, Mendoza B, Nakajima T, Robock A, Stephens G, Takemura T, Zhang H (2013) Anthropogenic and natural radiative forcing supplementary material. In: Stocker T, Qin D, Plattner G, Tignor M, Allen S, Boschung J, Nauels A, Xia Y, Bex V, Midgley P (eds) Climate change 2013: the physical science basis. Contribution of working group I to the fifth assessment report of the intergovernmental panel on climate change. Cambridge University Press, Cambridge, pp 8SM-1-44

Newell RG, Pizer WA (2003) Regulating stock externalities under uncertainty. Journal of Environmental Economics and Management 45(2):416-432

Newell RG, Pizer WA (2008) Indexed regulation. J Environ Econ Manag 56(3):221-233

Nordhaus W (1993) Rolling the "DICE': an optimal transition path for controlling greenhouse gases. Resour Energy Econ 15(1):27-50

Nordhaus W (2008) A question of balance: weighing the options on global warming policies. Yale University Press, New Haven

Nordhaus W (2014) Estimates of the social cost of carbon: concepts and results from the DICE-2013R model and alternative approaches. J Assoc Environ Resour Econ 1(1/2):273-312

Nordhaus W, Sztorc P (2013) DICE 2013R: introduction and user's manual, 2nd edn. http://www.econ.yale. edu/ nordhaus/homepage/homepage/documents/DICE_Manual_100413r1.pdf

Pearce D (2003) The social cost of carbon and its policy implications. Oxf Rev Econ Policy 19(3):362-384

Phillips KL, Evans RW (2017) Linearization about the current state: a computational method for approximating nonlinear policy functions during simulation. https://www.researchgate.net/publication/31297 0394_Linearization_about_the_Current_State_A_Computational_Method_for_Approximating_Nonli near_Policy_Functions_during_Simulation

Pigou AC (1932) The economics of welfare, 4th edn. McMillan\&Co, London

Prescott EC (1986) Theory ahead of business-cycle measurement. In: Carnegie-Rochester conference series on public policy 25. pp 11-44. Reprinted in Fed. Reserve Bank Minneapolis Q. Rev. 10 (Fall 1986): 9-22

Ravn MO, Uhlig H (2002) On adjusting the Hodrick-Prescott filter for the frequency of observations. Rev Econ Stat 84(2):371-376

Schmitt-Grohé S, Uribe M (2004) Solving dynamic general equilibrium models using a second-order approximation to the policy function. J Econ Dyn Control 28(4):755-775

Shine KP, Derwent RG, Wuebbles DJ, Morcrette JJ (1990) Radiative forcing of climate. In: Houghton JT, Jenkins G, Ephraums JJ (eds) Climate change-the IPCC scientific assessment, ch. 2. Cambridge University Press, Cambridge, pp 41-68

Stavins RN (1996) Correlated uncertainty and policy instrument choice. J Environ Econ Manag 30(2):218-232

Stern N (2007) The economics of climate change: the stern review. Cambridge University Press, Cambridge

Tokarska KB, Gillett NP, Weaver AJ, Arora VK, Eby M (2016) The climate response to five trillion tonnes of carbon. Nat Clim Change 6:851-855

UNFCCC (2015) Adoption of the Paris agreement. Report no. FCCC/CP/2015/L.9/Rev.1, http://unfccc.int/ resource/docs/2015/cop21/eng/109r01.pdf

van den Bijgaart I, Gerlagh R, Liski M (2016) A simple formula for the social cost of carbon. J Environ Econ Manag 77:75-94

van den Bijgaart IM, Smulders S (2018) Does a recession call for less stringent environmental policy? A partial-equilibrium second-best analysis. Environ Resource Econ 70(4):807-834

van den Bremer TS, van der Ploeg F (2019) The risk-adjusted carbon price. CESifo working paper 7592, Center for Economic Studies and ifo Institute (CESifo), Munich

Weitzman ML (1974) Prices vs. quantities. Rev Econ Stud 41(4):477-491

Wigley TML (1987) Relative contributions of different trace gases to the greenhouse effect. Clim Monit 16(1):14-28

Publisher's Note Springer Nature remains neutral with regard to jurisdictional claims in published maps and institutional affiliations. 